The Impact of Atmospheric Storminess on the Sensitivity of Southern Ocean Circulation to Wind Stress Changes

D.R. Munday, X. Zhai

PII: S1463-5003(17)30067-7

DOI: 10.1016/j.ocemod.2017.05.005

Reference: OCEMOD 1208

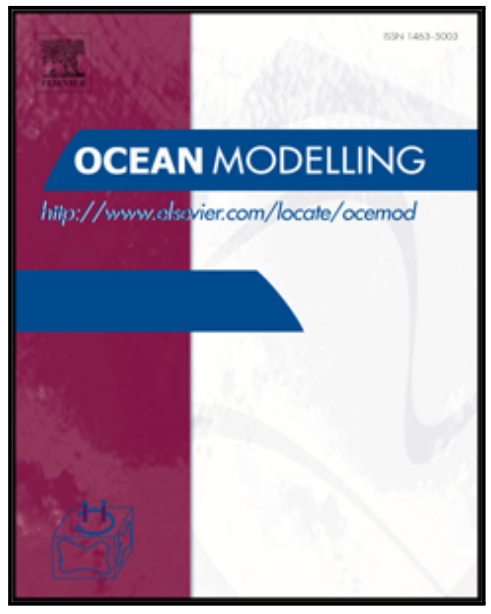

To appear in:

Ocean Modelling

Received date:

27 February 2017

Revised date:

4 May 2017

Accepted date:

13 May 2017

Please cite this article as: D.R. Munday, X. Zhai, The Impact of Atmospheric Storminess on the Sensitivity of Southern Ocean Circulation to Wind Stress Changes, Ocean Modelling (2017), doi: 10.1016/j.ocemod.2017.05.005

This is a PDF file of an unedited manuscript that has been accepted for publication. As a service to our customers we are providing this early version of the manuscript. The manuscript will undergo copyediting, typesetting, and review of the resulting proof before it is published in its final form. Please note that during the production process errors may be discovered which could affect the content, and all legal disclaimers that apply to the journal pertain. 


\section{Highlights}

- Increased wind stress can be caused by increased mean atmospheric wind or increased variability of the atmospheric wind.

- The impact of atmospheric wind variability is tested in an idealised Southern Ocean channel model.

- Overturning circulation is more sensitive to wind stress changes when the stress is altered due to changes in variability.

- Increase in sensitivity tied to changes in near-surface dissipation and the dissipation mechanism for kinetic energy. 


\title{
The Impact of Atmospheric Storminess on the Sensitivity of Southern Ocean Circulation to Wind Stress Changes
}

\author{
D.R. Munday ${ }^{\mathrm{a}, \mathrm{b}, *}$, X. Zhai ${ }^{\mathrm{c}, \mathrm{d}}$ \\ ${ }^{a}$ British Antarctic Survey, High Cross, Madingley Road, Cambridge, CB30 OET, UK \\ ${ }^{b}$ Atmospheric, Oceanic and Planetary Physics, Department of Physics, University of \\ Oxford, Oxford, OX1 3PU, UK \\ ${ }^{c}$ School of Environmental Sciences, University of East Anglia, Norwich, UK. \\ ${ }^{d}$ School of Marine Science, Nanjing University of Information Science and Technology, \\ Nanjing, China.
}

\begin{abstract}
The influence of changing the mean wind stress felt by the ocean through alteration of the variability of the atmospheric wind, as opposed to the mean atmospheric wind, on Southern Ocean circulation is investigated using an idealised channel model. Strongly varying atmospheric wind is found to increase the (parameterised) near-surface viscous and diffusive mixing. Analysis of the kinetic energy budget indicates a change in the main energy dissipation mechanism. For constant wind stress, dissipation of the power input by surface wind work is always dominated by bottom kinetic energy dissipation. However, with time-varying atmospheric wind, near surface viscous dissipation of kinetic energy becomes increasingly important as mean wind stress increases. This increased vertical diffusivity leads to thicker mixed layers and

*Corresponding author

Email addresses: danday@bas.ac.uk (D.R. Munday), xiaoming.zhai@uea.ac.uk (X. Zhai)
\end{abstract}


higher sensitivity of the residual circulation to increasing wind stress, when compared to equivalent experiments with the same wind stress held constant in time. This may have implications for Southern Ocean circulation in different climate change scenarios should the variability of the atmospheric wind change rather than the mean atmospheric wind.

Keywords: Ocean modelling, Eddy-resolving, Eddy kinetic energy, Surface wind stress, Residual overturning, Near-surface mixing

\section{Introduction}

2 ${ }_{16}$ merical models allows the emergence of two dynamical phenomena that have 17 been dubbed eddy saturation and eddy compensation. 
Eddy saturation refers to the loss of sensitivity of the volume transport of a circumpolar current to changes in wind stress (Hallberg and Gnanadesikan, 2006; Tansley and Marshall, 2001). This loss of sensitivity can extend to the limit of no zonal wind stress (Munday et al., 2013) and changes in the sensitivity can be linked to the zonal momentum balance of the current (Munday et al., 2015). The degree of eddy saturation that a given model configuration achieves is subject to subtleties due, for example, to the inclusion of shallow coastal areas (Hogg and Munday, 2014) or the structure of the wind forcing (Nadeau and Straub, 2009, 2012).

Eddy compensation is the reduced sensitivity to changes in wind stress of the RMOC when eddies are resolved or permitted (Viebahn and Eden, 2010; Abernathey et al., 2011). Although complimentary to eddy saturation, eddy compensation is dynamically distinct (Meredith et al., 2012; Morrison and Hogg, 2013). Like eddy saturation, the degree to which a particular model's RMOC is compensated depends on several different aspects of the model including, but not limited to, whether the surface buoyancy forcing is fixed flux vs. restoring to a fixed buoyancy (Abernathey et al., 2011, henceforth AMF11) and even the particular timescale used in the restoring condition (Zhai andMunday, 2014, henceforth ZM14).

Investigations into eddy saturation and eddy compensation using numerical models typically involve varying the magnitude of the mean wind stress in the Southern Ocean, without concern as to whether this variation is due to changes in the mean atmospheric wind or atmospheric variability. In practice, changes of the mean stress may be brought about by either, owing to the nonlinear dependence of the wind stress on the wind (Zhai, 2013). This is 
64

${ }_{65}$ there is a shift in the energy balance such that more energy is dissipated

66 by vertical viscous processes with respect to a stormless control experiment. 
This enhanced dissipation is found to be sensitive to the strength of the wind stress and the propagation speed and strength of the storms, with increases in any of these leading to further enhancement of the viscous dissipation.

Turbulent mixing associated with energy dissipation is also likely to contribute to water mass transformation processes in the surface diabatic layer. Wind stress variability can play a direct role in mode water formation yia the destruction or creation of potential vorticity at ocean fronts (Thomas, 2005) or by generating wave-induced vertical mixing (Shu et al., 2011). Changes in the mode of variability of atmospheric wind, i.e. ENSO or the Southern Annular Mode, has been observed to change the dominant creation mechanism for Subantarctic Mode Water (Naveira Garabato et al., 2009). In other words, there may be a role for wind-induced near-inertial energy and/or wind variability to play in the emergence of eddy saturation and compensation due to changes in the mode and intensity of near surface dissipation.

In this paper we aim to investigate how changing the wind stress felt by the ocean via an increase in the variability of the atmospheric wind, instead of the mean wind, impacts upon eddy saturation and eddy compensation. In Section 2 we give a brief description of the experimental design and model domain. Section 3 describes the circulation achieved at the control wind stress. Section 4 discusses the sensitivity to wind stress of the model's energy budget under conditions of varying wind. Section 5 discusses the sensitivity of the Southern Ocean circulation to wind stress changes. We close with a 9 summary and discussion of our results in Section 6. 


\section{Experimental Design}

In order to investigate the impact of time-varying atmospheric wind on Southern Ocean dynamics we adopt the idealised MIT general circulation model (MITgcm, see Marshall et al., 1997a,b) configuration of AMF11, adapted to a coarser grid spacing by ZM14 and used by Munday and Zhai (2015, henceforth MZ15) to investigate the role of relative wind stress, in which the effect of ocean current speed on surface wind stress is taken into account, on Southern Ocean circulation. The model domain is a zonally reentrant channel that is $1000 \mathrm{~km}$ in zonal extent, nearly $2000 \mathrm{~km}$ in meridional extent, and $2985 \mathrm{~m}$ deep with a flat bottom. There are 33 geopotential levels whose thickness increase with depth, ranging from $10 \mathrm{~m}$ at the surface to $250 \mathrm{~m}$ for the bottom-most level.

The horizontal grid spacing is chosen to be $10 \mathrm{~km}$, which is sufficiently fine so as to permit a vigorous eddy field without incurring undue computational cost. Strictly speaking, this grid spacing makes the model eddy-permitting, rather than eddy-resolving, since it does not resolve the first baroclinic deformation radius throughout the model domain. In particular, it cannot resolve the eddy formation process. However, when mature, i.e. at their maximum size/strength, eddies are typically several deformation radius across. Furthermore, this grid spacing is fine enough that substantial eddy saturation of the zonal transport occurs in domains with bottom bathymetry (Munday et al., 2015). As such, we deem it sufficient for our purposes.

[Table 1 about here.]

We employ the K-profile parameterisation (KPP) vertical mixing scheme 
(Large et al., 1994) and a linear bottom friction. The equation of state is linear and only temperature variations are considered. The model is set on a $\beta$-plane. Parameter values for bottom friction, viscosity, etc, are as given in Table 1. The schematic in Fig. 2 indicates the meridional cross-section of the model configuration and forcing, including the northern boundary sponge (see below for details).

[Figure 2 about here.]

The model's potential temperature, $\theta$, is forced by a constant heat flux at the surface and restored to a prescribed stratification in a sponge layer within $100 \mathrm{~km}$ of the northern boundary. The surface heat flux is given by

$$
Q(y)= \begin{cases}-Q_{0} \sin \left(3 \pi y / L_{y}\right), & \text { for } y<L_{y} / 3 \\ 0, & \text { for } y>L_{y} / 3\end{cases}
$$

where $Q_{0}$ is the magnitude if the flux and $L_{y}$ is the meridional extent of the domain, as per AMF11 and ZM14, with $y=0 \mathrm{~km}$ placed at the centre of the domain following MZ15. This broadly describes the observed distribution of surface buoyancy flux around the SO (see Fig. 1 of AMF11). Within $100 \mathrm{~km}$ of the northern boundary, potential temperature is restored to the stratification given by

$$
\theta_{N}(z)=\Delta \theta\left(e^{z / h_{e}}-e^{-H / h_{e}}\right) /\left(1-e^{-H / h_{e}}\right)
$$

${ }_{132}$ This describes exponential decay with depth from a surface temperature given by $\Delta \theta$ to 0 at depth $-H$ (the total depth of the domain) with an 
(1)

$e$-folding scale height of $h_{e}$. The restoring time scale for the sponge varies from $\infty$ (no restoring) at the southern edge of the sponge to 7 days at the northern edge of the domain. The sponge restoring profile and surface heat flux are as shown in Figs. 3a and 3b, respectively.

[Figure 3 about here.]

In contrast to AMF11 and ZM14, we do not prescribe the wind stress in all of our experiments. Instead we prescribe $10 \mathrm{~m}$ atmospheric wind velocity and use the bulk formulae of Large and Pond (1981) to calculate the wind stress. These formulae use arguments based on vertical turbulent transport to represent the transfer of momentum between the atmosphere and the ocean as a stress. MZ15 use so-called relative wind stress, which applies the most physically complete bulk formula given by

$$
\boldsymbol{\tau}_{\text {relative }}=\rho_{a} c_{d}\left|\mathbf{U}_{10}-\mathbf{u}_{s}\right|\left(\mathbf{U}_{10}-\mathbf{u}_{s}\right)
$$

where $\mathbf{U}_{10}=\left(U_{10}, V_{10}\right)$ is the $10 \mathrm{~m}$ (atmospheric) wind velocity, $\mathbf{u}_{s}=\left(u_{s}, v_{s}\right)$ is the surface ocean velocity, $\rho_{a}$ is air density, and $c_{d}$ is a drag coefficient, which itself is a weak function of $\mathbf{U}_{10}-\mathbf{u}_{s}$.

MZ15 found that the use of relative wind stress had little effect on the sensitivity of the SO RMOC to wind stress and that eddy saturation still emerged. In addition, initial experiments combining variable atmospheric winds with the relative wind stress formulation indicated that, in this particular model domain, the impact of relative wind stress was swamped by the time-varying winds. Therefore, in the interests of clarity, we choose to neglect the surface ocean currents in the calculation of wind stress and instead 
use the resting ocean approximation. In this limit, the wind stress is given by

$$
\boldsymbol{\tau}=\rho_{a} c_{d}\left|\mathbf{U}_{10}\right| \mathbf{U}_{10} .
$$

Further, we split the wind into a mean component, $\overline{\mathbf{U}}_{10}$, and a perturbation, $\mathbf{U}_{10}^{\prime}$, such that $\mathbf{U}_{10}=\overline{\mathbf{U}}_{10}+\mathbf{U}_{10}^{\prime}$, allowing us to write

$$
\boldsymbol{\tau}=\rho_{a} c_{d}\left|\overline{\mathbf{U}}_{10}+\mathbf{U}_{10}^{\prime}\right|\left(\overline{\mathbf{U}}_{10}+\mathbf{U}_{10}^{\prime}\right)
$$

In our experiments, the mean $10 \mathrm{~m}$ atmospherio wind velocity, $\overline{\mathbf{U}}_{10}$, is given by

$$
\overline{\mathbf{U}}_{10}=\mathbf{U}_{0} \cos \left(\pi y / L_{y}\right),
$$

where $\mathbf{U}_{0}=\left(U_{x}, U_{y}\right)$ is the peak wind velocity in the zonal and meridional direction. This is the same profile of mean wind as used by MZ15. In contrast to MZ15, we specify $U_{x}=7 \mathrm{~ms}^{-1}$ and $U_{y}=0 \mathrm{~ms}^{-1}$ and vary $\mathbf{U}_{10}^{\prime}$ with pseudo-random perturbations to change $\boldsymbol{\tau}$, instead of increasing $U_{x}$.

In our first set of experiments, referred to as the stochastic wind experiments, additive white Gaussian noise is used to perturb the wind profile given by Eq. (6). Every six hours a pseudo-random number from a standard normal distribution is generated using the polar algorithm attributed to Marsaglia and Bray (1964). Each experiment uses the same sequence of pseudo-random numbers, which does not repeat over the life of the experiments.

To generate the wind perturbation, the sequence of pseudo-random numbers is multiplied by the desired standard deviation of the wind speed, $\sigma_{\tau}$. The wind profile of Eq. (6) is then uniformly adjusted by this amount, e.g. 
if a perturbation of $3.21 \mathrm{~ms}^{-1}$ is generated, the peak zonal wind would be $10.21 \mathrm{~ms}^{-1}$ and the minimum wind at the northern and southern boundary would be $3.21 \mathrm{~ms}^{-1}$. This is illustrated in Fig. 3c by the grey shading, which shows the wind profile for one standard deviation of $9 \mathrm{~ms}^{-1}$ to either side of the mean zonal wind profile given by Eq. (6).

We use values of $\sigma_{\tau}$ of $0,3,6,9,12,15,18$ and $21 \mathrm{~ms}^{-1}$. The experiment with a standard deviation of $9 \mathrm{~ms}^{-1}$ is chosen as the control since this matches the roughly constant standard deviation of the NCEP winds over the Southern Ocean, as shown in Fig. 1a. This value of $\sigma_{\tau}$ gives a peak mean wind stress of $0.17 \mathrm{Nm}^{-2}$, which is close to the mean NCEP wind stress in Fig. 1b (blue line) and the control experiments of AMF11, ZM14 and MZ15. The mean wind stress that results for $\sigma_{\tau}=0,9$, and $21 \mathrm{~ms}^{-1}$ are shown in Fig. 3d. The peak wind stress that results from the different values of $\sigma_{\tau}$ are shown in Fig. 4 with the control experiment highlighted using a hexagram. The resulting relationship is roughly quadratic, as one would from Eq. (4), with a weak cubic term due to $c_{d}$ also varying weakly with $\mathbf{U}_{10}$.

Figure 4 about here.]

The second set of experiments are forced by 50-year averages of the wind stress from the stochastic wind experiments. These will be referred to as the equivalent stress experiments. By diagnosing the wind stress from the stochastic wind experiments we ensure the same pattern of mean wind stress. However, because these experiments use a constant pattern of wind stress they are effectively changing $\overline{\mathbf{U}}_{10}$, instead of $\mathbf{U}_{10}^{\prime}$, to alter the mean wind stress. This is expected to have a different impact upon the near-inertial 


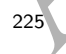

\section{,}

wave field and other near surface mixing processes, and thus may impact upon the sensitivity of the circumpolar transport and meridional overturning to changes in wind stress.

The stochastic wind experiments are begun from the end of the 800 year statistically steady control experiment of ZM14. The experiments have the wind stress used by ZM14 replaced with the zonal wind as described above and are run for a further 400 years. At the end of this second phase of spin up we take a 50 year average of the zonal wind stress and use this to drive the equivalent wind stress experiments. Both the stochastic and equivalent wind stress experiments are then run to statistical equilibrium. All our results are drawn from a final 50 year diagnostic phase in which long-term averages are made. There is a slight discrepancy in the peak wind stress for this diagnostic run between the stochastic wind experiments and the equivalent stress experiments. This is due to the pseudo-random nature of the wind perturbations for the stochastic wind stress experiments, which are only an approximation to a true normal distribution, and the finite length of the diagnostic run. This discrepancy is $<0.5 \%$ for the control experiments and $\sim 1.5 \%$ for the extremes.

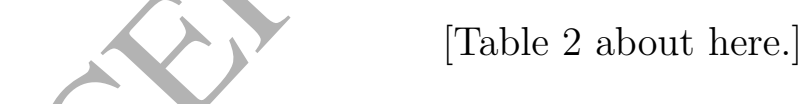

\section{The Control State}

3.1. Zonal Circulation of the Control State

Due to the flat bottomed nature of the model domain, the time-average flow is zonally-symmetric with time-mean streamlines and temperature contours running east-west. This is much the same as in AMF11, ZM14 and 
251 The very large $T_{b}$ of both control experiments is a consequence of the 252

MZ15. Nevertheless, instantaneously a vigorous mesoscale eddy field is present resulting in complex non-zonal streamlines and temperature contours. EKE is likewise zonally symmetric with higher values towards the centre of the channel and close to the surface. In both control experiments, peak values of EKE at the surface exceed $0.05 \mathrm{~m}^{2} \mathrm{~s}^{-1}$, which is typical in observed estimates and high resolution models (see, e.g., Delworth et al., 2012). However, the zonal-mean EKE values are somewhat elevated/due to the strong zonal symmetry and lack of EKE localisation by bottom bathymetry. This tends to give high values throughout the channel.

Following MZ15 and Munday et al. (2015), we decompose the total circumpolar transport, $T_{A C C}$, into the bottom transport, $T_{b}$, and the thermal wind transport, $T_{t w}$, such that $T_{A C C} \neq T_{b}+T_{t w}$. The bottom transport is simply the flow in the bottom model level integrated over the full crosssectional area of the channel. The thermal wind transport is then calculated as the residual of $T_{A C C}$ and $T_{b}$ and is what would be obtained from using the temperature field in a thermal wind shear calculation.

The total circumpolar transport of the stochastic wind stress control, with a peak wind stress of $0.17 \mathrm{Nm}^{-2}$, is $621 \mathrm{~Sv}$. Of this $542 \mathrm{~Sv}$ resides in $T_{b}$ and $78 \mathrm{~Sv}$ in $T_{t w}$. The circumpolar transport for the equivalent stress control experiment varies slightly from the stochastic control (see Table 2), with a $T_{b}$ of $548 \mathrm{~Sv}$ and a $T_{t w}$ of $82 \mathrm{~Sv}$. This is due to the slight discrepancy in the wind stress, noted in Section 2, and differences in isopycnal slope between the two control experiments.

252 momentum balance in a flat bottomed channel, which leads to the bottom 
flow accelerating until surface momentum input from the wind is balanced by bottom friction (see, e.g., Gill and Bryan, 1971; Bryan and Cox, 1972). The approximate momentum balance of the channel can be written as

$$
\frac{\left\langle\bar{\tau}_{x}\right\rangle}{\rho_{0}} \approx r_{b}\left\langle\bar{u}_{b}\right\rangle
$$

where $\left\langle\bar{\tau}_{x}\right\rangle$ is the time and zonal average of the zonal wind stress, $\left\langle\bar{u}_{b}\right\rangle$ is the time and zonal average zonal velocity in the bottom level of the model, $\rho_{0}$ is the Boussinesq reference density, and $r_{b}$ is the linear bottom friction coefficient. Since $\left\langle\bar{\tau}_{x}\right\rangle, \rho_{0}$ and $r_{b}$ are the same for both control experiments, the zonally-averaged zonal flow in their model bottom level, $\left\langle\bar{u}_{b}\right\rangle$, must also be roughly the same. In a model with bathymetry high enough so as to block geostrophic contours, the near bottom flow is much weaker and $T_{b}$ correspondingly lower (see, e.g, Munday et al., 2015).

The thermal wind transport of both controls is below that of the real ACC, which recent estimates place at around 134Sv (Meredith et al., 2011). This is due to a combination of factors that include the cross-channel temperature difference being lower than in some parts of the SO and the stratification also being potentially shallower than in some locations. These would combine to give a lower thermal wind shear than in the real SO and therefore a lower $T_{t w}$

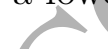

3.2. Residual Overturning of the Control State

[Figure 5 about here.]

Following AMF11 and ZM14/MZ15, the model's residual overturning, $\Psi_{\text {res }}$, is calculated using temperature as the vertical coordinate and re-binning 
the model's meridional velocities into temperature layers $0.2^{\circ} \mathrm{C}$ thick. This is an online calculation that includes information from every model timestep to ensure that high frequency motions are captured. The RMOC is then mapped back to vertical coordinates using the time and zonal mean thickness of each temperature layer. The bolus overturning, $\Psi^{*}$, due to the integral effects of the vigorous mesoscale eddy field, can then be calculated as the difference between $\Psi_{\text {res }}$ and the Eulerian overturning, $\bar{\Psi}$, calculated from the time-average meridional velocity field.

Broadly speaking the RMOCs for the two control experiments look very similar to, and have much in common with, the control experiment RMOCs of AMF11 and ZM14/MZ15. As shown in Fig. 5, they consist of model analogues of the clockwise North Atlantic Deep Water (NADW) cell and the anticlockwise Antarctic Bottom Water (AABW) cell. An Antarctic Intermediate Water (AAIW) cell also forms near the northern boundary, close to the northern boundary restoring zone. The most noticeable difference between the two RMOC's in Fig. 5 is that the stochastic wind stress experiment has slightly stronger upwelling in its NADW cell and a slightly weaker AABW cell.

In terms of the Southern Ocean's actual RMOC, both the stochastic and equivalent stress control experiments are of the right order of magnitude, with peak values of the NADW cell at $0.72 \mathrm{~Sv}$ and $0.61 \mathrm{~Sv}$, respectively. Scaling the model domain up to the full extent of the real SO, a factor of 20-25, would give peak values of $14.4-18 \mathrm{~Sv}$ and $12.2-15.25 \mathrm{~Sv}$. Estimates place the upwelling of the Southern Ocean in the 10-20Sv range (Marshall et al., 2006; Lumpkin and Speer, 2007). 
Fig. 5 also shows that the mixed layer, defined as above the depth at which the water is $0.8^{\circ} \mathrm{C}$ colder than the surface (above the grey line in Fig. 5, see, e.g., Kara et al. (2000), for details), is slightly deeper for the stochastic wind stress control. This is consistent with the increased yertical viscosity/diffusivity provided by KPP as a result of the stochastic variation of the wind stress leading to surface-intensified mixing. These are reported in Table 2 as domain average values of $45 / 42 \mathrm{~cm}^{2} \mathrm{~s}^{-1}$ for the stochastic control, compared with $24 / 18 \mathrm{~cm}^{2} \mathrm{~s}^{-1}$ for the equivalent wind stress control. This elevated mixing drives deepening of the mixed layer, as noted above, and may make contributions to, for example, the budgets of momentum, kinetic energy, temperature and temperature variance.

\section{Sensitivity of the Energy Budget to Wind Stress Variability}

\subsection{Simple Energy Budget Diagnostics}

[Figure 6 about here.]

As $\sigma_{\tau}$ increases in the stochastic wind stress experiments, the peak wind stress increases as per Fig. 4, as it also does for the equivalent wind stress experiments by construction. The stronger wind stress also does more work at the surface, and thus power input into the model's circulation is higher. Despite the mean wind stress being the same, the stochastic wind stress experiments have considerably more power entering the circulation via surface wind work than the equivalent wind stress experiments (Fig. 6a, cf. blue and red dots). This is due to the strong correlation in time between the stochastic perturbations to the wind stress and the resulting ocean currents. 
The surface wind work can be Reynolds averaged to write $\overline{\boldsymbol{\tau} \cdot \mathbf{u}_{s}}=\overline{\boldsymbol{\tau}}$. $\overline{\mathbf{u}}_{s}+\overline{\boldsymbol{\tau}^{\prime} \cdot \mathbf{u}_{s}^{\prime}}$, with the subscript $s$ indicating surface values. Diagnosis of this decomposition for the stochastic wind stress experiments shows that an increasingly large fraction of the power input from the wind stress comes from the wind stress perturbations acting upon the velocity perturbations (Fig. 6a, cf. blue and green dots). However, the work done by the mean wind on the mean flow, i.e. the first term on the right-hand side of the above decomposition, remains comparable to the total wind work in the equivalent wind stress experiments (Fig. 6a, cf. red and green dots).

Surface wind work is estimated to input approximately 1TW of power into the ocean circulation, with about half of this occurring in the SO (Wunsch and Ferrari, 2004; Ferrari and Wunsch, 2009). The power input in the two control simulations is $0.071 \mathrm{TW}$ and $0.044 \mathrm{TW}$ for the stochastic wind stress and equivalent wind stress control experiments, respectively. Scaling this up to the full extent of the SO, using a factor of 20-25, gives figures of $1.42-1.78 \mathrm{TW}$ and $0.88-1.1 \mathrm{TW}$. Both these figures are over-estimates caused by the strong zonal surface flow that results from using a flat bottom and thus very strong correlation between the surface currents and the wind stress. However, it is the surface wind stress operating on the baroclinic shear that provides the power to drive the eddy energy (Abernathey et al., 2011) and so this excess power input should not invalidate our results.

Following Cessi et al. (2006) and Cessi (2008), the leading order mechanical eddy budget of the model is expected to be

$$
\left\langle\overline{\boldsymbol{\tau} \cdot \mathbf{u}_{s}}\right\rangle \approx \rho_{0} r_{b}\left\langle\overline{\mathbf{u}_{b} \cdot \mathbf{u}_{b}}\right\rangle
$$


349

Applying Reynolds averaging to Eq. (8) gives

$$
\left\langle\overline{\boldsymbol{\tau}} \cdot \overline{\mathbf{u}}_{s}\right\rangle+\left\langle\overline{\boldsymbol{\tau}^{\prime} \cdot \mathbf{u}_{s}^{\prime}}\right\rangle \approx \rho_{0} r_{b}\left\langle\overline{\mathbf{u}}_{b} \cdot \overline{\mathbf{u}}_{b}\right\rangle+\rho_{0} r_{b}\left\langle\overline{\mathbf{u}_{b}^{\prime} \cdot \mathbf{u}_{b}^{\prime}}\right\rangle .
$$

This approximate budget states that the power input by the surface wind work is balanced by bottom friction dissipation acting on the total kinetic energy. Due to the flat bottomed nature of the channel, we must retain the mean kinetic energy dissipation on the right-hand-side of Eq. (9).

The left- and right-hand sides of Eq. (9) are diagnosed in Fig. 6b. The blue dots show the total power input due to wind stress against the total bottom dissipation, i.e. the left-hand side of Eq. (8) plotted against its right-hand side, for the stochastic wind stress experiments. The red dots are the same diagnostics for the equivalent wind stress experiments. However, the green dots plot the total bottom dissipation against the power input from the mean wind acting on the mean flow, i.e. the right-hand side of Eq. (9) against only the first term on its left-hand side. This highlights that the strong correlation between the time-varying wind and the time-varying ocean currents provides more power than the resulting flow can dissipate by bottom friction processes alone. In contrast, the bottom dissipation of total kinetic energy is sufficient to roughly balance the total wind work for the equivalent wind stress experiments (Fig. 6b, red dots).

[Figure 7 about here.]

In a viscid fluid, viscosity redistributes momentum and dissipates energy, and so changes in viscosity can affect the dissipation of total kinetic energy. Examining the average diffusivities and viscosities that KPP calculates shows 
a large increase over the range of wind forcing considered. In particular, the vertical diffusivity/viscosity for any given stochastic wind stress experiment is always higher than its in partner equivalent wind stress experiment, see Fig. 7. The "missing" energy dissipation may therefore be accounted for by vertical viscous dissipation. It is also possible that horizontal viscous forces may remain equally, or more, important than vertical ones. Therefore, in Section 4.2 we turn to a more complete estimate of the sinks and sources of power within the model via the mechanical energy framework of Winters et al. (1995).

\subsection{Full Power Budget Diagnostics}

Deriving a full mechanical energy budget for the ocean, particularly in the presence of a nonlinear equation of state, is complicated by the large gravitational potential energy of its stratification. This has led to a number of different formulations based upon the earlier work of Winters et al. (1995). The key difference between these formulations lies in their treatment of the background gravitational potential energy, e.g. Tailleux $(2009,2013)$ vs. Hughes et al (2009) and Saenz et al. (2012), and the amount available for potential energy to kinetic energy conversions. Recently, dynamical potential energy was proposed as a way to eliminate some of the complications inherent to calculations of Available Potential Energy (APE) by defining a new pressure variable (Roquet, 2013).

A complete treatment of the (available) potential energy, and thus the full mechanical energy budget, is beyond the scope of this paper. Instead, we concentrate on the changes to the kinetic energy budget due to a stochastic wind stress and outline the framework of Winters et al. (1995), using the 


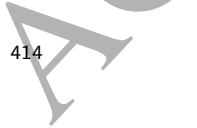

notation due to Hughes et al. (2009) and Hogg et al. (2013).

The volume integrated kinetic energy budget for a Boussinesq fluid is given by (Winters et al., 1995; Hughes et al., 2009; Hogg et al., 2013)

$$
\rho_{0} \frac{\partial E_{k}}{\partial t}=\Phi_{\tau}-\Phi_{z}-\Phi_{r}-\epsilon
$$

where $E_{k}$ is the volume integrated kinetic energy given by

$$
E_{k}=\frac{1}{2} \int_{V} \overline{u^{2}+v^{2}} \mathrm{~d} V
$$

and $V$ is the volume of the model ocean. Henceforth, we assume statistical steady state such that the left-hand-side of Eq. (10) is zero. $\Phi_{\tau}$ is the power source due to surface wind stress, $\Phi_{z}$ is the conversion between kinetic and potential energy, $\Phi_{r}$ is the power sink due to bottom friction, and $\epsilon$ is the power sink due to viscous stresses.

Surface wind stress does work on the surface currents and so acts as a source of power. For a time-varying wind stress, such as in our stochastic wind stress experiments, there are two components to the surface wind work, as per Eq. (9). The first is due to the mean wind stress acting on the mean surface velocities, $\Phi_{\bar{\tau}}$, and the second is due to wind stress perturbations acting on the surface perturbation velocities, $\Phi_{\tau^{\prime}}$, i.e. $\Phi_{\tau}=\Phi_{\bar{\tau}}+\Phi_{\tau^{\prime}}$. These two components are given by

$$
\begin{aligned}
\Phi_{\bar{\tau}} & =\int_{S} \overline{\boldsymbol{\tau}} \cdot \overline{\mathbf{u}}_{s} \mathrm{~d} S \\
\Phi_{\tau^{\prime}} & =\int_{S} \overline{\boldsymbol{\tau}^{\prime} \cdot \mathbf{u}^{\prime}}{ }_{s} \mathrm{~d} S
\end{aligned}
$$


${ }_{433}^{432} \quad \epsilon_{v}=\rho_{0} \int_{V} \overline{A_{v} \frac{\partial \mathbf{u}_{h}}{\partial z} \cdot \frac{\partial \mathbf{u}_{h}}{\partial z}} \mathrm{~d} V$,

where the subscript $h$ implies the horizontal component of the vector under consideration. Note that the vertical viscosity, $A_{v}$, may vary in time due ${ }_{436}$ to the use of the KPP parameterisation and is harmonic. In contrast, the ${ }_{437}$ horizontal biharmonic viscosity, $A_{4}$, is a constant in space and time.

The dissipation of kinetic energy due to viscous stresses is divided into two parts, that due to horizontal viscosity, $\epsilon_{h}$, and that due to vertical viscosity, $\epsilon_{v}$, i.e. $\epsilon=\epsilon_{h}+\epsilon_{v}$. These two components are given by 


\subsection{Sensitivity to Wind Stress of the Full Power Budget}

Estimates of $\Phi_{\bar{\tau}}, \Phi_{\tau^{\prime}}, \Phi_{r}, \epsilon_{h}$ and $\epsilon_{v}$ were obtained from the 50-year diagnostic run at statistical steady state. The changes that the sources and sinks undergo is best illustrated by considering the control wind stress and extreme wind stress cases for the stochastic and equivalent wind stress experiments. It is also useful to consider both the absolute and relative magnitude for each term, as done in Figure 8. This highlights that there are changes in the partitioning of dissipation between bottom friction and vertical viscous dissipation as the variability of the atmospheric wind changes.

[Figure 8 about here.]

As the variability of the wind increases, so does the surface wind stress, as shown in Fig. 4, and thus the power source to the ocean circulation also increases (Fig. 6a). In terms of the framework outlined in Section 4.2, $\Phi_{\bar{\tau}}$ and $\Phi_{\tau^{\prime}}$ both increase. However, the fraction of the total power input that comes from the mean wind stress acting on the mean ocean velocities decreases. For the extreme stochastic wind stress experiment, roughly $2 / 3$ of the total power provided to the ocean circulation by the wind is due to $\Phi_{\tau^{\prime}}$. In contrast, at the control wind stress around $1 / 3$ of the power input to the ocean comes from $\Phi_{\tau^{\prime}}$ (Fig. 8b, 1st and 3rd columns).

For all of the equivalent wind stress experiments, $\Phi_{\tau^{\prime}}=0$ by construction, and so the source of power at the surface is reduced. However, the magnitude of $\Phi_{\bar{\tau}}$ remains roughly the same between matched pairs of equivalent and stochastic wind stress experiments (see Figs. 6a and 8a, 3rd and 7th columns). 
For the extreme wind stress experiments, there is a disparity between the time-mean vertical viscosity that is provided by KPP between pairs of stochastic and equivalent wind stress experiments (see Fig. 7a). The equivalent wind stress extreme shows an increase in magnitude for the dissipation of $\mathrm{KE}$ due to vertical viscosity, relative to the control experiment (cf. Fig. 8a, 6th and 8th columns). However, the fraction of dissipation is roughly the same as the control (cf. Fig. 8b, 6th and 8th column). This is a strong contrast with the stochastic wind stress extreme experiment, which has more power dissipated by vertical viscosity than it does by linear bottom friction (Fig. 8a, 4th column). Furthermore, the fraction of power dissipated by vertical viscosity also increases between the stochastic wind stress control and extreme (Fig. 8b, 2nd and 4th column). This fractional increase is roughly in proportion to the fractional increase in power supplied by $\Phi_{\tau^{\prime}}$ with respect to $\Phi_{\bar{\tau}}$.

In summary, increasing the wind power input to the ocean causes an increase in the power dissipated by bottom friction. However, in the case of the stochastic wind stress experiments, the increase in the power dissipated by vertical viscous processes, i.e. KPP, increases by a greater proportion. This leads to a change in the dominant power dissipation mechanism, consistent with the results of Jouanno et al. (2016). For both sets of experiments, the change in energy dissipation due to horizontal viscosity remains relatively small. This increase in vertical viscous dissipation is brought about by the increase in the vertical viscosity provided by KPP (see Fig. 7). 


\section{Sensitivity to Wind Stress of the Circulation}

\subsection{Sensitivity to Wind Stress of the Temperature Field and Zonal Transport}

[Figure 9 about here.]

The increase in KPP's vertical viscosity shown in Fig. 7b alters the power budget of the model, such that at extreme wind stress variability more power is dissipated by vertical viscous processes than bottom friction. The increase in KPP's vertical diffusivity may also influence the model by dissipating temperature variance/potential energy. However, rather than diagnose the potential energy budget, it is simpler to examine the temperature structure as an overall summary of stratification and thermal wind shear changes.

The impact of the buoyancy budget alteration by high near-surface vertical diffusivity can be seen in Fig. 9, which shows the time and zonal average of potential temperature for the control and extreme experiments. The control experiments in Fig. 9a have similar stratification, allowing for the slightly deeper mixed layer in the stochastic control. For the extreme stochastic experiment in Fig. 9b, the-1ncrease in the mixed layer diffusivity has led to nearly vertical isotherms near the surface, but flatter isotherms at depth than the extreme equivalent experiment. This reduces the cross-channel buoyancy difference over most of the depth for the extreme stochastic wind stress experiment. Hence, its $T_{t w}$ is lower than the extreme equivalent wind stress experiment. In fact, as shown in Fig. 10 the control stochastic wind stress experiment actually has the highest $T_{t w}$ of all the stochastic experiments.

[Figure 10 about here.] 
At low wind stresses, $\tau_{0}<0.2 \mathrm{Nm}^{-2}$, both sets of experiments have very similar $T_{t w}$. At these low stresses, not all isotherms outcrop at the surface, and so the cross-channel buoyancy difference is lower than in the two controls, leading to a reduced $T_{t w}$. As the wind stress increases, the two sets of experiments differ from each other. For the equivalent wind stress experiments, $T_{t w}$ increases quasi-linearly, much as with the experiments of MZ15. However, the thermal wind transport of the stochastic wind stress experiments begins to decrease and all 4 experiments with a peak mean wind stress greater than the control actually have a lower $T_{t w}$ than the control. This is most likely due to the exceptionally large changes in the diffusivity that KPP prescribes as $\sigma_{\tau}$ increases. Whilst this steepens the isopycnals in the mixed layer, it leads to less steep isopycnals outside of the mixed layer, essentially via geometry, and a reduced cross-channel buoyancy difference.

At a finer grid spacing, and/or higher wind stress, both the stochastic and equivalent wind stress may demonstrate a higher degree of eddy saturation than that in Fig. 10. However, it is impossible to say without running the experiments at considerable computational expense. It seems likely, however, that, should further inereases in wind stress saturate the transport, then the stochastic wind stress experiments would achieve a substantially lower final transport than the equivalent wind stress experiments.

Changing wind stress can also alter $T_{A C C}$ by $T_{b}$. However, by construction, the equivalent wind stress experiments use wind stress diagnosed from their stochastic partner. Hence, matched pairs of experiments have very similar $T_{b}$ (not shown). 

554 strength of the AABW cell.

555 556 experiments (see Table 2).

\subsection{Sensitivity to Wind Stress of the RMOC}

[Figure 11 about here.]

To examine the sensitivity of the RMOC to changes in wind stress, the RMOC is first quantified in a simple manner. To do so, we use the same method as AMF11 and select the maximum and minimum value of $\Psi_{\text {res }}$ below $500 \mathrm{~m}$ and $100 \mathrm{~km}$ south of the edge of the sponge region. These values are labeled $\Psi_{\text {upper }}$ and $\Psi_{\text {lower }}$ for the NADW and AABW cells, respectively. As qualitatively described in Section 3.2, $\Psi_{\text {upper }}$ and $\Psi_{\text {lower }}$ indicate a stronger NADW but weaker AABW cell under stochastic wind) stress for the control

Fig. 11a shows the variation of $\Psi_{\text {upper }}$ and $\Psi_{\text {lower }}$ (blue/red symbols respectively) across both sets of experiments, as well as the maximum Eulerian overturning ( $\bar{\Psi}_{\max }$, black dots) for the stochastic wind stress experiments as a comparison. The difference between $\Psi_{\text {upper }}$ for the stochastic and equivalent wind stress experiments becomes accentuated at peak mean wind stresses $>0.2 \mathrm{Nm}^{-2}$. In contrast, $\Psi_{\text {lower }}$ shows that there is little real difference in the sensitivity AABW cell across the wide range of wind stresses considered. The value of $\Psi_{\text {lower }}$ for the stochastic wind stress experiment where $\sigma_{\tau}=21 \mathrm{~ms}^{-1}$ is something of an outlier. The extreme variability of the wind has caused the mixed layer to deepen to such an extent that it impinges upon the upper limit, $500 \mathrm{~m}$, of the streamfunction values tested for this diagnostic. As a result, $\Psi_{\text {lower }}$ starts to represent the mixed layer overturning rather than the

Using residual mean theory the RMOC's streamfunction can be written as the sum of the Eulerian mean $\operatorname{MOC}(\bar{\Psi})$ and the eddy-induced bolus 
557

558

overturning $\left(\Psi^{*}\right)$ (see, e.g., Marshall and Radko, 2003), i.e.

$$
\Psi_{\mathrm{res}}=\bar{\Psi}+\Psi^{*}=-\frac{\left\langle\bar{\tau}_{x}\right\rangle}{\rho_{0} f}+K s
$$

where $f$ is the Coriolis parameter, $K$ is the quasi-Stokes/eddy diffusivity for the buoyancy field $\left(b=-g\left(\rho-\rho_{0}\right) / \rho_{0}\right)$ and $s=-\bar{b}_{y} / \bar{b}_{z}$ is the isopycnal slope. Following MZ15, we take small perturbations around Eq. (18) and write

$$
\Delta \Psi_{\mathrm{res}} \approx-\frac{\Delta \bar{\tau}_{x}}{\rho_{0} f}+\Delta K s_{0}+K_{0} \Delta
$$

where $K_{0}$ and $s_{0}$ are the eddy diffusivity and isopycnal slope of a chosen equivalent wind stress experiment. Dividing by $\Psi_{0}^{*}=K_{0} s_{0}$, the unperturbed bolus overturning, and writing $\Delta \bar{\Psi}=-\Delta \bar{\tau}_{x} / \rho_{0} f$, the change in the residual overturning as a fraction of the original bolus overturning is related to changes in mean wind stress,$$
\frac{\Delta \Psi_{\mathrm{res}}}{\Psi_{0}^{*}} \approx \frac{\Delta \bar{\Psi}}{\Psi_{0}^{*}}+\frac{\Delta K}{K_{0}}+\frac{\Delta s}{s_{0}}
$$

By construction, $\Delta \bar{\Psi} \approx 0$ between pairs of stochastic wind stress and equivalent wind stress experiments. Therefore, fractional changes in the residual overturning between pairs must be related to a combination of changes in isopycnal slope and eddy diffusivity. If there were no changes in $\Delta \Psi_{\text {res }} / \Psi_{0}^{*}$, then the fractional change in isopycnal slope can be simply related to the fractional change in eddy diffusivity, i.e.

$$
\frac{\Delta s}{s_{0}} \approx-\frac{\Delta K}{K_{0}}
$$


8

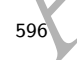

We have already seen that increasing $\sigma_{\tau}$ leads to reduced (more positive) isopycnal slopes, which gives $\Delta s / s_{0}<0$. This implies that to maintain the RMOC at the equivalent wind stress experiment values, the eddy diffusivity of the stochastic wind stress experiments would have to increase. This would be consistent with the elevated levels of EKE seen in the stochastic wind stress experiments. However, these elevated levels are biased to the near surface values and it is the isopycnal slope and eddy diffusivity outside of the mixed layer that set $\Psi_{\text {res }}$

To quantitatively examine the relationship encoded in Eqs. (20) and (21), we diagnose the mean eddy diffusivity in each of our experiments using a simple flux gradient closure, i.e.

$$
\left\langle\overline{v^{\prime} \theta^{\prime}}\right\rangle=-K\left\langle\frac{\partial \bar{\theta}}{\partial y}\right\rangle .
$$

The eddy diffusivity and isopycnal slope are then averaged over the central $500 \mathrm{~km}$ of the channel between depths of $1100 \mathrm{~m}$ and $1800 \mathrm{~m}$. Perturbations are taken between pairs of stochastic wind stress and equivalent wind stress experiments, with the equivalent wind stress experiment taken as the initial solution for the purposes of Eq. (20).

[Figure 12 about here.]
Plotting $-\Delta K / K_{0}$ against $\Delta s / s_{0}$ in Fig. 12a shows that the fractional
change in eddy diffusivity is of the opposite sense to that required for main-
words, both the isopycnal slope and eddy diffusivity has decreased between
pairs of equivalent and stochastic wind stress experiments. This means that 
the bolus overturning must decrease and the RMOC must also change, as previously highlighted in Fig. 11. In effect, the decrease in the bolus overturning allows more of the Eulerian mean flow to show and the result is a stronger RMOC under stochastic wind stress.

As a final check on Eq. (20), we have also included $\Delta \Psi_{\text {res }} / \Psi_{0}^{*}$ and $\Delta \Psi / \Psi_{0}^{*}$ on the $\mathrm{y}$-axis of Fig. 12b. In this case, the relationship holds well, indicating that the neglected terms that are quadratic in perturbation terms in Eq. (20) are small and that our diagnosis of the eddy diffusivity and isopycnal slope are accurate enough to properly capture the physics of the changes.

\section{Discussion and Conclusions}

The Southern Ocean is important to climate because of its residual circulation and the Antarctic Circumpolar Current, which allow for meridional and zonal exchange of properties between ocean basins (Meredith et al., 2011). Understanding the processes and mechanisms that set its circulation, and its sensitivity to changing forcing, are therefore of paramount importance to understanding global climate.

Numerous numerical models indicate that the sensitivity to wind stress of the RMOC and volume transport of the ACC are reduced in the presence of a resolved or permitted eddy field (see, e.g., Hallberg and Gnanadesikan, 2006; Munday et al., 2013). Many investigations into these phenomena rely upon the use of idealised wind stress patterns that are constant in time. However, the mean wind stress felt by the ocean is a function of both the mean atmospheric wind and its variability. Changing a constant mean wind stress implicitly assumes that the stress is becoming greater due to a stronger 
mean wind.

Here we have investigated the impact that changing the variability of the atmospheric wind, whilst keeping the mean atmospheric wind constant, has upon the Southern Ocean circulation. We performed two sets of experiments with the same mean wind stress. The stochastic wind stress experiments had their atmospheric wind altered by a pseudo-random number from a white Gaussian distribution every 6 hours. This random number was multiplied by a chosen standard deviation to give a range of wind stress. The equivalent wind stress experiments are driven by the time-mean wind from their corresponding stochastic wind stress partner.

At the control wind stress of $\sim 0.17 \mathrm{Nm}^{-2}$ there are only minor differences between the stochastic and equivalent wind stress circulations. The RMOC is composed of NADW and AABW cells of similar strength (see Table 2) and the circumpolar transport due to thermal wind shear is also similar. This implies that there is also only minor changes in the north-south buoyancy difference across the channel and thus the isopycnal slope. The mixed layer is deeper with stochastic wind stress, which gives stronger viscosity/diffusivity in the mixed layer from the KPP parameterisation.

As the mean wind stress is altered, the stochastic and equivalent wind stress experiments deviate from each other in terms of their RMOC and circumpolar transport. The deep RMOC of the equivalent wind stress experiments is less sensitive to the changing wind stress than in their stochastic partners. In addition, the equivalent wind stress experiments show indications of the emergence of eddy saturation. This contrasts with the stochastic wind stress experiments, for which an increase in the variability of the at- 
648

mospheric wind, and thus the mean wind stress, results in a reduction of the circumpolar transport.

Diagnosis of the power budget for kinetic energy indicates that the rise in viscosity/diffusivity from KPP goes hand-in-hand with an increase in power dissipation due to vertical viscosity. This results in a change in the dominant power dissipation mechanism, from bottom drag to near-surface yiscous processes, for the stochastic wind stress experiments as the variability of the wind is increased. This may well be accompanied by changes in energy pathways between, e.g., forcing and EKE. For example, in a simple channel model with a periodically varying wind stress, Sinha and Abernatbey (2016) see peaks in the EKE spectra corresponding to wind variation with periodicity of longer than a year. However, the APE spectra continues to display peaks for higher frequency wind forcing. At these high frequencies, they find the conversion from APE to EKE is small and relate this to changes in the pathways between energy reservoirs. Proper verification of such a change in our model would require diagnosis of the (available) potential energy and its budget.

The increased near-surface vertical temperature diffusivity deepens the mixed layer and ultimately results in flatter isotherms over most of the channel. These flatter isotherms eventually lead to a decrease in circumpolar transport with/ncreasing wind variability, which contrasts with the increasing circumpolar transport seen in the equivalent wind stress experiments. In addition, the flatter isotherms ultimately reduce the eddy diffusivity such that te bolus overturning starts to weaken at high wind stress variability. This leads to a stronger sensitivity to wind stress of the RMOC in the stochastic wind stress experiments as more of the Eulerian overturning is "seen" in 
the residual flow.

Our main conclusion is that changes in the variability of the atmospheric wind may lead to considerably different sensitivity of the RMOC and volume transport of the ACC than that caused by blowing a stronger mean wind over the ocean. In this model, KPP interprets the increased near surface shear due to the variable wind as increased viscous and diffusive mixing. This deepens the mixed layer and contributes a strong diabatic/aspect to the near-surface RMOC. It is something of a concern that this conclusion is so strongly tied to a parameterised, rather than resolved, physical process. This is because it is possible that KPP may notbe representing the instability and mixing processes in a completely physical way, i.e. KPP translates the increased near-surface shear into near-surface mixing without allowing for, e.g., the vertical propagation of waves that might lead to increased mixing at depth. Such vertical propagation would surely produce different degrees of eddy saturation and eddy compensation than in our simple flat-bottomed channel model. However, even if the response of KPP is not precisely correct in physical terms, our results indicate that assessing whether wind stress changes due to increasing mean wind or increasing variability is of potential concern for the response of the ocean circulation and climate as a whole.

The real ocean is predominantly inviscid. However, our conclusion, that the dominant kinetic energy sink may change from bottom friction processes to near-surface mixing processes and lead to altered sensitivity of the ocean's stratification and RMOC to wind stress, can still hold in these conditions. This is because KPP is parameterising a number of mixing processes. Whilst these processes may not be viscous and/or diffusive in the real ocean, this 

${ }_{721}$ / under more variable wind forcing, is therefore the next step. influence their sensitivity to wind stress changes could remain. budget can be expected to be that of Cessi et al. (2006) and Cessi (2008), i.e.

is how KPP represents them. Hence, the transition to a new dominant dissipative process is still valid, even if in the real ocean that process is not viscous or diffusive. In this case, whilst the details of how the stratification and RMOC change may differ, that a change in the energy budget could

The geometry and complexity of the real ocean's bottom bathymetry is not well represented by our model's flat bottom. This could potentially be troublesome in the SO, where bottom form stresses across large bathymetric obstacles balances the momentum input from the wind (Munk and Palmén, 1951; Johnson and Bryden, 1989). This is our (reason for primarily focussing on the energy budget of the ocean in our analysis; pressure gradients, and by extension bottom form stresses, do not enter into the energetics framework of Winters et al. (1995) or play a role in the energy cycle (Ferrari and Wunsch, 2009). As a result, even with large bottom bathymetry, the zero order power surface wind work balanced by bottom EKE dissipation. The key change here from our model's budget is that we must retain the dissipation from mean bottom currents in Eqs. (8) and (9). The strong bottom flow in our flat bottomed model also leads to a disproportionately large power input. These could combine to potentially influence the level of wind variability required to bring about a transition in the dominant energy dissipation mechanism in a model with complex bathymetry and more realistic power input. The assessment of the power budget in such a model, and how the budget changes 


\section{Acknowledgements}

DRM is supported by the Natural Environment Research Council [ORCHESTRA, grant number NE/N018095/1].. Much of this work took place whilst DRM was a PDRA at the Department of Physics in the University of Oxford and was supported by the UK Natural Environment Research Council. DRM thanks Scott Bachman and Alberto Naveira Garabate for helpful discussions. The authors thank two anonymous reviewers whose comments improved the presentation of the paper. This work made use of the facilities of HECToR, the UK's national high-performance computing service, which is provided by UoE HPCx Ltd at the University of Edinburgh, Cray Inc and NAG Ltd, and funded by the Office of Science and Technology through EPSRC's High End Computing Programme. This work used the ARCHER UK National Supercomputing Service (http://www.archer.ac.uk). Model output is available from DRM upon request.

\section{References}

Abernathey, R., Marshall, J., Ferreira, D., 2011. The dependence of Southern Ocean meridional overturning on wind stress. J. Phys. Oceanogr. 41, 22612278 .

Bryan, K. Cox, M. D., 1972. An approximate equation of state for numerical models of ocean circulation. J. Phys. Oceanogr. 2, 510-517.

Bryden, H. L., 1979. Poleward heat flux and conversion of available potential energy in Drake Passage. J. Mar. Res. 37, 1-22. 
Cessi, P., 2008. An energy-constrained parameterization of eddy buoyancy flux. J. Phys. Oceanogr. 38, 1807-1820.

Cessi, P., Young, W. R., Polton, J. A., 2006. Control of large-scale heat transport by small-scale mixing. J. Phys. Oceanogr. 36, 1877-1894.

Delworth, T. L., Rosati, A., Anderson, W., Adcroft, A. J., Balaji, V., Benson, R., Dixon, K., Griffies, S. M., Lee, H.-C., Pacanowski, R. C., Vecchi, G. A., Wittenberg, A. T., Zeng, F., Zhang, R., 2012. Simulated climate and climate change in the GFDL CM2.5 high-resolution coupled climate model. J. Clim. 25, 2755-2781.

Ferrari, R., Wunsch, C., 2009. Ocean circulation kinetic energy: Reservoirs, sources, and sinks. Annu. Rev. Fluid Mech. 41, 253-282, doi:10.1146/annurev.fluid.40.111406.102139.

Furuichi, N., Hibiya, T., Niwa, Y., 2008. Model-predicted distribution of wind-induced internat wave energy in the world's ocean. J. Geophys. Res. 113, C09034, doi:10.1029/2008JC004768.

Gill, A. E., Bryan, K., 1971. Effects of geometry on the circulation of a three-dimensional southern-hemisphere ocean model. Deep-Sea Res. 18, $685-721$.

Hallberg, R., Gnanadesikan, A., 2006. The role of eddies in determining the structure and response of the wind-driven southern hemisphere overturning: Results from the Modeling Eddies in the Southern Ocean (MESO) project. J. Phys. Oceanogr. 36, 2232-2252. 

$786 \quad 471$.

Hogg, A. M., Dijkstra, H. A., Saenz, J. A., 2013. The energetics of a collapsing meridional overturning circulation. J. Phys. Oceanogr. 43, 1512-1524.

Hogg, A. M., Munday, D. R., 2014. Does the sensitivity of Southern Ocean circulation depend upon bathymetric details? Phil. Trans. R. Soc A 372, 20130050, doi:10.1098/rsta.2013.0050.

Hughes, G. O., Hogg, A. M., Griffiths, R. W., 2009. Available potential energy and irreversible mixing in the meridional overturning circulation. J. Phys. Oceanogr. 39, 3130-3146.

Jayne, S. R., Marotzke, J., 2002. The oceanic eddy heat transport. J. Phys. Oceanogr. 32, 3328-3345.

Johnson, G. C., Bryden, H. L., 1989. On the size of the Antarctic Circumpolar Current. Deep-Sea Res. 36, 39-53.

Jouanno, J., Capet, X., Madec, G., Roullet, G., Klein, P., 2016. Dissipation of the energy imparted by mid-latitude storms in the southern ocean. Ocean Sci. 12, 743-769, doi:10/5194/os-12-743-2016.

Kalnay, E, Kanamitsu, M., Kistler, R., Collins, W., Deaven, D., Gandin, L., Iredell, M., Saha, S., White, G., Woollen, J., Zhu, Y., Chelliah, M., Ebisuzaki, W., Higgins, W., Janowiak, J., Mo, K. C., Ropelewski, C., Wang, J., Leetmaa, A., Reynolds, R., Jenne, R., Joseph, D., 1996. The NCEP/NCAR 40-year reanalysis project. Bull. Amer. Met. Soc. 77, 437- 
787

Kara, A. B., Rochford, P. A., Hurlburt, H. E., 2000. An optimal definition for ocean mixed layer depth. J. Geophys. Res. 105, 16 803-16821, doi:10.1029/2000JC900072.

Large, W. G., McWilliams, J. C., Doney, S. C., 1994. Oceanic vertical mixing: A review and a model with a nonlocal boundary layer parameterization. Rev. Geophys. 32, 363-403.

Large, W. G., Pond, S., 1981. Open ocean momentum flux measurements in moderate to strong winds. J. Phys. Oceanogr. 11, 324-336.

Lumpkin, R., Speer, K., 2007. Global ocean meridional overturning. J. Phys. Oceanogr. 37, 2550-2562, doi:10.1175/JPO3130.1.

Marsaglia, G., Bray, T. A., 1964. A conveniant method for generating normal variables. SIAM Rev. 6, 260-264, doi:10.1137/1006063.

Marshall, J., Adcroft, A., Hill, C., Perelman, L., Heisey, C., 1997a. A finite volume, incompressible Navier-Stokes model for studies of the ocean on parallel computers. J. Geophys. Res. 102, 5753-5766.

Marshall, J., Hill, C., Perelman, L., Adcroft., A., 1997b. Hydrostatic, quasihydrostatic, and non-hydrostatic ocean modeling. J. Geophys. Res. 102, $5733-5752$.

Marshall, J., Radko, T., 2003. Residual-mean solutions for the Antarctic Circumpolar Current and its associated overturning circulation. J. Phys. Oceanogr. 33, 2341-2354. 
Marshall, J., Shuckburgh, E., Jones, H., Hill, C., 2006. Estimates and implications of surface eddy diffusivity in the Southern Ocean derived from tracer transport. J. Phys. Oceanogr. 36, 1806-1821.

Meijers, A. J., Bindoff, N. L., Roberts, J. L., 2007. On the total, mean, and eddy heat and freshwater transports in the southern hemisphere of a $\frac{1}{8}^{\circ} \times \frac{1}{8}^{\circ}$ global ocean model. J. Phys. Oceanogr. 37, 277-295.

Meredith, M. P., Naveira Garabato, A. C., Hogg, A. M., Farneti, R., 2012. Sensitivity of the overturning circulation in the Southern Ocean to decadal changes in wind forcing. J. Clim. 25, 99-110, doi:10.1175/2011JCLI4204.1.

Meredith, M. P., Woodworth, P. L., Chereskin, T. K., Marshall, D. P., Allison, L. C., Bigg, G. R., Donohue, K. Heywood, K. J., Hughes, C. W., Hibbert, A., Hogg, A. M., Johnson, H. L., King, B. A., Leach, H., Lenn, Y., Morales-Maqueda, M. A., Munday, D. R., Naveira-Garabato, A. C., Provost, C., Sprintall, J., 2011. Sustained monitoring of the Southern Ocean at Drake Passages past achievements and future priorities. Rev. Geophys. 49, RG4005, doi:10.1029/2010RG000348.

Morrison, A. K., Hogg, A. M., 2013. On the relationship between Southern Ocean overturning and ACC transport. J. Phys. Oceanogr. 43, 140-148.

Munday, D. R., Johnson, H. L., Marshall, D. P., 2013. Eddy saturation of equilibrated circumpolar currents. J. Phys. Oceanogr. 43, 507-532, doi:10.1175/JPO-D-12-095.1.

Munday, D. R., Johnson, H. L., Marshall, D. P., 2015. The role of ocean gateways in the dynamics and sensitivity to wind stress of the 
${ }_{851}$ Roquet, F., 2013. Dynamical potential energy: A new approach to ocean 852

early Antarctic Circumpolar Current. Paleoceanography 30, 284-302, doi:10.1002/2014PA002675.

Munday, D. R., Zhai, X., 2015. Sensitivity of Southern Ocean circulation to wind stress changes: Role of relative wind stress. Ocean Modell. 95, 15-24, doi:10.1016/j.ocemod.2015.08.004.

Munk, W. H., Palmén, E., 1951. Note on the dynamics of the Antarctic Circumpolar Current. Tellus 3, 53-55.

Nadeau, L. P., Straub, D. N., 2009. Basin and channel contributions to a model Antarctic Circumpolar Current. J. Phys. Oceanogr. 39, 986-1002.

Nadeau, L. P., Straub, D. N., 2012. Influence of wind stress, wind stress curl, and bottom friction on the transport of a model Antarctic Circumpolar Current. J. Phys. Oceanogr. 42, 207-222.

Naveira Garabato, A. C. Jullion, L., Stevens, D. P., Heywood, K. J., King, B. A., 2009. Variability of Subantarctic Mode Water and Antarctic Intermediate Water in the Drake Passage during the latetwentieth and early-twenty-first centuries. J. Clim. 22, 3661-3688, doi:10,1175/2009JCLI2621.1.

Rath, W., Greatbatch, R. J., Zhai, X., 2014. On the spatial and temporal distribution of near-inertial energy in the Southern Ocean. J. Geophys. Res. 119, 359-376, doi:10.1002/2013JC009246.

energetics. J. Phys. Oceanogr. 43, 457-476, doi: 10.1175/JPO-D-12-098.1. 
853

872 873

Saenz, J. A., Hogg, A. M., Hughes, G. O., Griffiths, R. W., 2012. Mechanical power input from buoyancy and wind to the circulation in an ocean model. Geophys. Res. Lett. 39, L13605, doi:10.1029/2012GL052035.

Shu, Q., Qiao, F., Song, Z., Xia, C., Yang, Y., 2011. Improvement of MOM4 by including surface wave-induced vertical mixing. Ocean Modell. 40,4251.

Sinha, A., Abernathey, R. P., 2016. Time scale of Southern Ocean eddy equilibration. J. Phys. Oceanogr. 46, 2785-2805, doi:10.1175/JPO-D-160041.1.

Tailleux, R., 2009. On the energetics of stratified turbulent mixing, irreversible thermodynamics, Boussinesq models and the ocean heat engine controversy. J. Fluid Mech. 638, 339-382.

Tailleux, R., 2013. Available potential energy and exergy in stratified fluids. Annu. Rev. Fluid Mech. 45, 35-58, doi:10.1146/annurev-fluid-011212140620.

Tansley, C. E., Marshall, D. P., 2001. On the dynamics of wind-driven circumpolar currents. J. Phys. Oceanogr. 31, 3258-3273.

Thomas, L. N., 2005. Destruction of potential vorticity by winds. J. Phys. Oceanogr. 35, 2457-2466.

Viébahn, J., Eden, C., 2010. Towards the impact of eddies on the response of the Southern Ocean to climate change. Ocean Modell. 34, 150-165. 
874

875

876

877

Winters, K. B., Lombard, P. L., Riley, J. J., D'Asaro, E. A., 1995. Available potential energy and mixing in density-stratified fluids. J. Fluid Mech. 289, $115-128$.

Wunsch, C., 1998. The work done by the wind on the oceanic general circulation. J. Phys. Oceanogr. 28, 2332-2340.

Wunsch, C., Ferrari, R., 2004. Vertical mixing, energy, and the general circulation of the oceans. Annu. Rev. Fluid Mech. 36, 281-314.

Zhai, X., 2013. On the wind mechanical forcing of the ocean general circulation. J. Geophys. Res. 118 (1-17, doi.1002/2013JC009086).

Zhai, X., Greatbatch, R. J., Eden, C., Hibiya, T., 2009. On the loss of windinduced near-inertial energy to turbulent mixing in the upper ocean. J. Phys. Oceanogr. 39, 3040-3045.

Zhai, X., Munday, D. R., 2014. Sensitivity of Southern Ocean overturning to wind stress changes: Role of surface restoring time scales. Ocean Modell. 84, 12-25, doi:10.1016/j.ocemod.2014.09.004. 


\section{List of Figures}

1 Atmospheric wind from the NCEP reanalysis (Kalnay et al., 1996). (a) Mean zonal wind at $10 \mathrm{~m}$ (blue) and square root of atmospheric EKE (red). (b) Mean wind zonal wind stress (blue) and wind stress from the mean zonal wind (red) calculated using the bulk formula of Large and Pond (1981).

2 Schematic of the model domain. The dashes at the surface mark where the heat flux is zero, with blue arrows showing regions of cooling and red arrows regions of heating. The grey shading near the northern boundary is the northern sponge. The symbols above the flux arrows show the wind forcing. The dashed lines schematically show the shape of the time-mean isotherms/isopycnals. . . . . . . . . . . . . . . 44

3 Model forcing as described in the text. (a) Northern boundary temperature restoring profile, (b) surface heat flux (positive into ocean), (c) atmospheric wind profile with grey shading showing one standard deviation about the mean for $\sigma_{\tau}=$ $9 \mathrm{~ms}^{-1}$, (d) corresponding surface wind stress. . . . . . . . 45

4 Variation in peak mean wind stress as the standard deviation of the atmospheric wind is varied. The peak mean wind stress of the control experiments is highlighted with a hexagram. . . 46

5 RMOC (in Sverdrups) at the control wind stress for (a) stochastic wind stress and (b) equivalent wind stress. Black contours are the zonal-time-average potential temperature $\left({ }^{\circ} \mathrm{C}\right)$ and the colours are the RMOC with red indicating clockwise flow. The grey contour is the mixed layer depth from KPP, defined as the depth at which the water is $0.8^{\circ} \mathrm{C}$ colder than the surface, see, e.g. Kara et al. (2000), for details. . . . . . . . . . . . . . 4

6 Sensitivity to wind stress changes of energy budget diagnostics. (a) Power input vs. maximum wind stress and (b) bottom EKE dissipation vs. power input. The thin black in line in (b) has a gradient of 1 and highlight the departure from the simple relationship of Eq. (8). The control experiments are highlighted with hexagrams. . . . . . . . . . . . . 44 
7 Domain average (a) viscosity and (b) temperature diffusivity as provided by the KPP parameterisation versus the maximum wind stress. The control experiments are highlighted with hexagrams. . . . . . . . . . . . . . . . . 49 49

8 Bar charts of the power budget for the control and extreme wind stress case for both stochastic and equivalent wind stress experiments. Presented as (a) absolute magnitude of the terms (b) relative to the total power input from the wind of each individual experiment. . . . . . . . . . . . 50

9 Contours of time and zonal average potential temperature, every $0.5^{\circ} \mathrm{C}$ starting at $0.5^{\circ} \mathrm{C}$, for paired stochastic (blue) and equivalent (red) wind stress experiments. (a) Control wind stress, with $\sigma_{\tau}=9 \mathrm{~ms}^{-1}$, for the stochastic experiment. (b) Extreme wind stress, with $\sigma_{\tau}=21 \mathrm{~ms}^{-1}$, for the stochastic experiment. . . . . . . . . . . . . . 5 51

10 "Baroclinic" transport, as per $T_{t w}$ vs. maximum wind stress. The control experiments are highlighted with hexagrams. . . . 52

11 Sensitivity of the RMOC to changing wind stress across all experiments. Maximum Eulerian overturning in the domain $\left(\bar{\Psi}_{\max }\right.$, black dots) and maximum/minimum $\left(\Psi_{\text {upper }} / \Psi_{\text {lower }}\right.$, round/square) RMOC $100 \mathrm{~km}$ south of the northern restoring zone and below $500 \mathrm{~m}$ for the stochastic/equivalent wind stress experiments (blue/red). The control experiments are highlighted with hexagrams. . . . . . . . . . . . . . . 53

12 Quantitative tests of residual mean relationship between changes in eddy diffusivity and isopycnal slope. (a) Excluding any MOC changes, as per Eq. (21), (b) full relationship as per Eq. (20) including wind stress and MOC changes. The difference is taken between the equivalent and stochastic wind stress experiments with the equivalent wind stress experiment of each pair used as the initial state. The dotted lines cross at the origin and the solid line has a gradient of $1 . \ldots . . . . .554$ 
a) Atmospheric wind

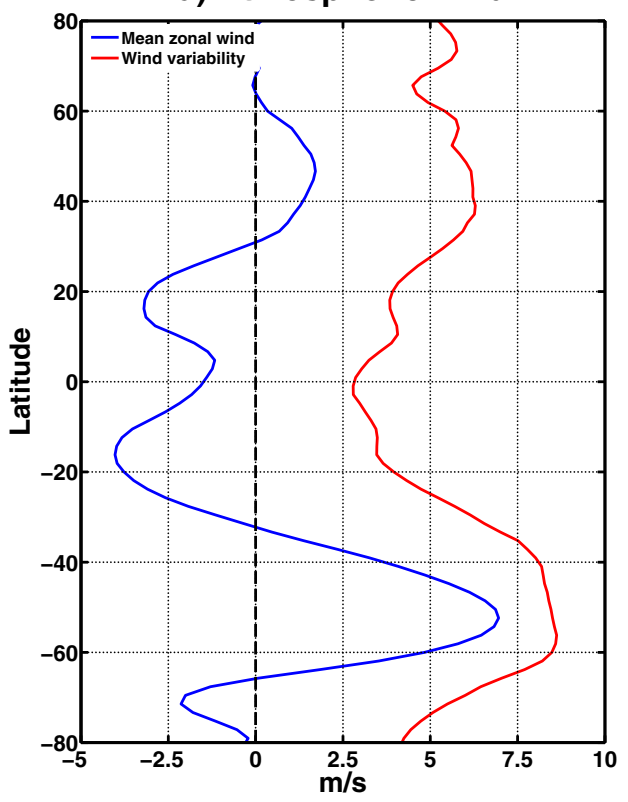

\section{b) Wind stress}

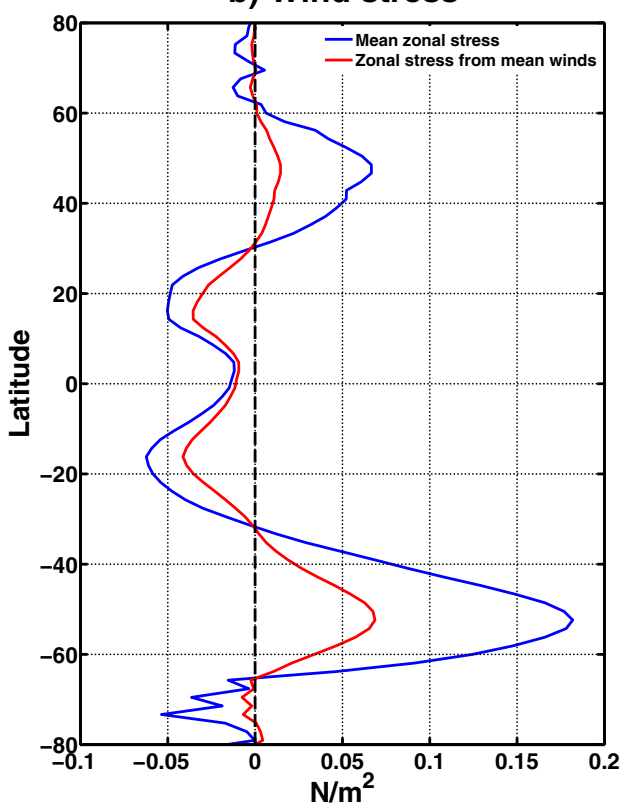

Figure 1: Atmospheric wind from the NCEP reanalysis (Kalnay et al., 1996). (a) Mean zonal wind at $10 \mathrm{~m}$ (blue) and square root of atmospheric EKE (red). (b) Mean wind zonal wind stress (blue) and wind stress from the mean zonal wind (red) calculated using the bulk formula of Large and Pond (1981). 


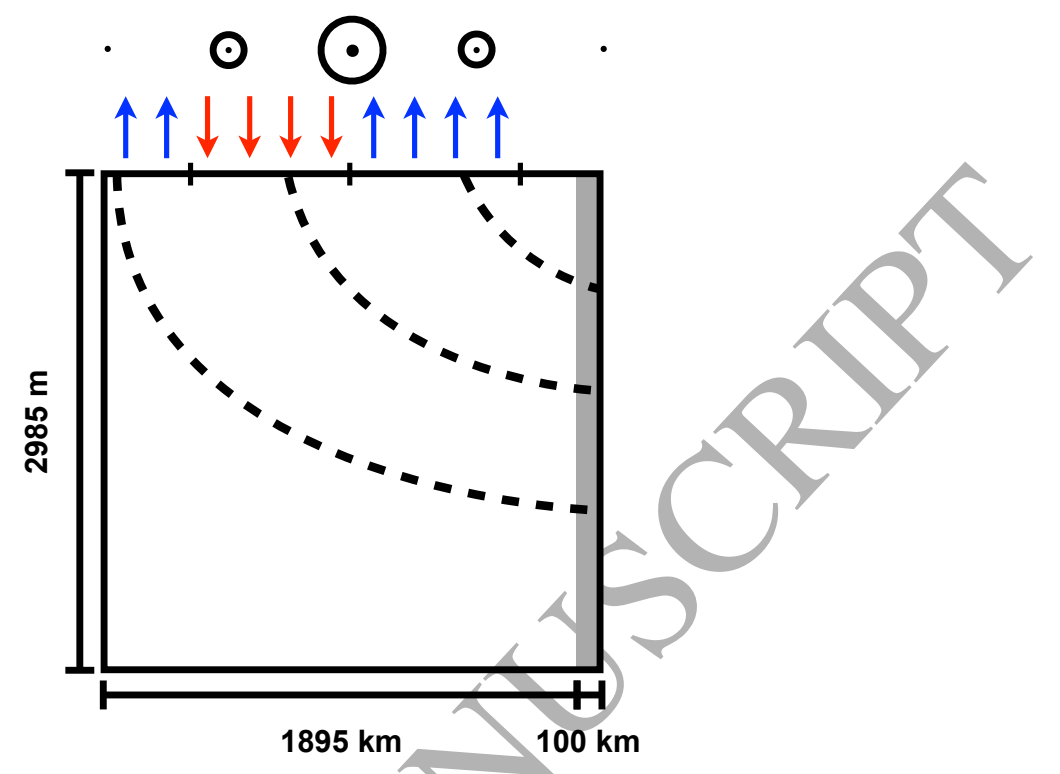

Figure 2: Schematic of the model domain. The dashes at the surface mark where the heat flux is zero, with blue arrows showing regions of cooling and red arrows regions of heating. The grey shading near the northern boundary is the northern sponge. The symbols above the flux arrows show the wind forcing. The dashed lines schematically show the shape of the time-mean isotherms/isopycnals. 
a) $T_{N}$

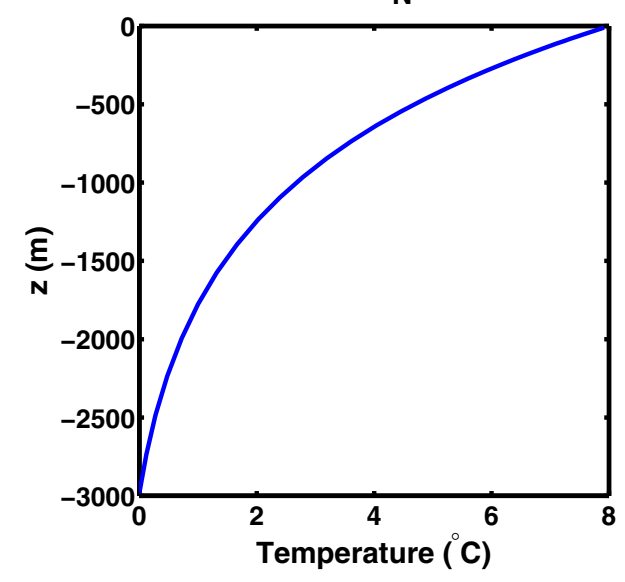

c) $U_{10}$

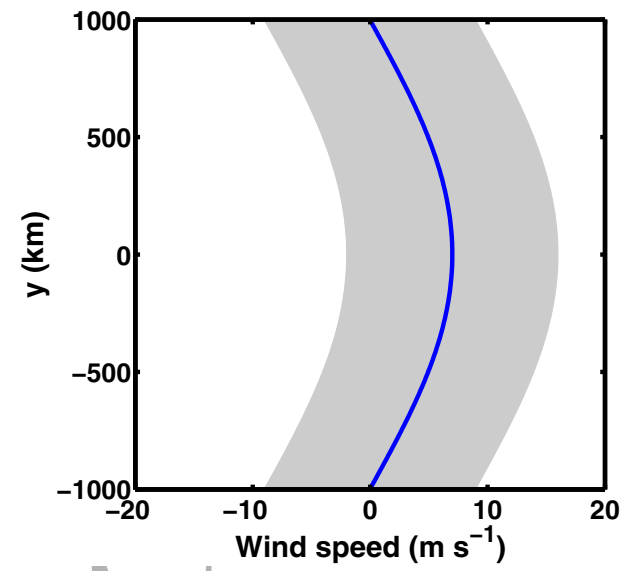

b) $Q$

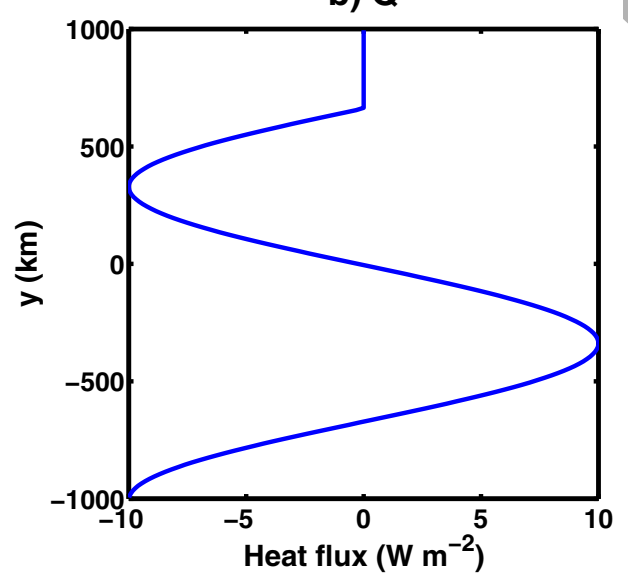

d) $\tau_{x}$

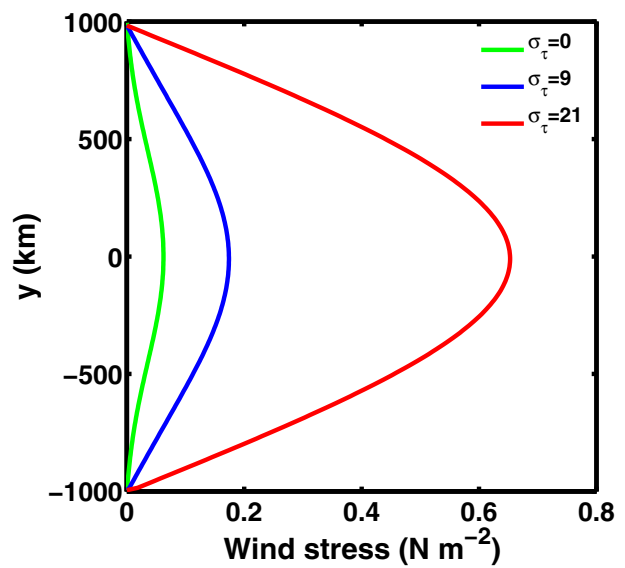

Figure 3: Model forcing as described in the text. (a) Northern boundary temperature restoring profile, (b) surface heat flux (positive into ocean), (c) atmospheric wind profile with grey shading showing one standard deviation about the mean for $\sigma_{\tau}=9 \mathrm{~ms}^{-1}$, (d) corresponding surface wind stress. 


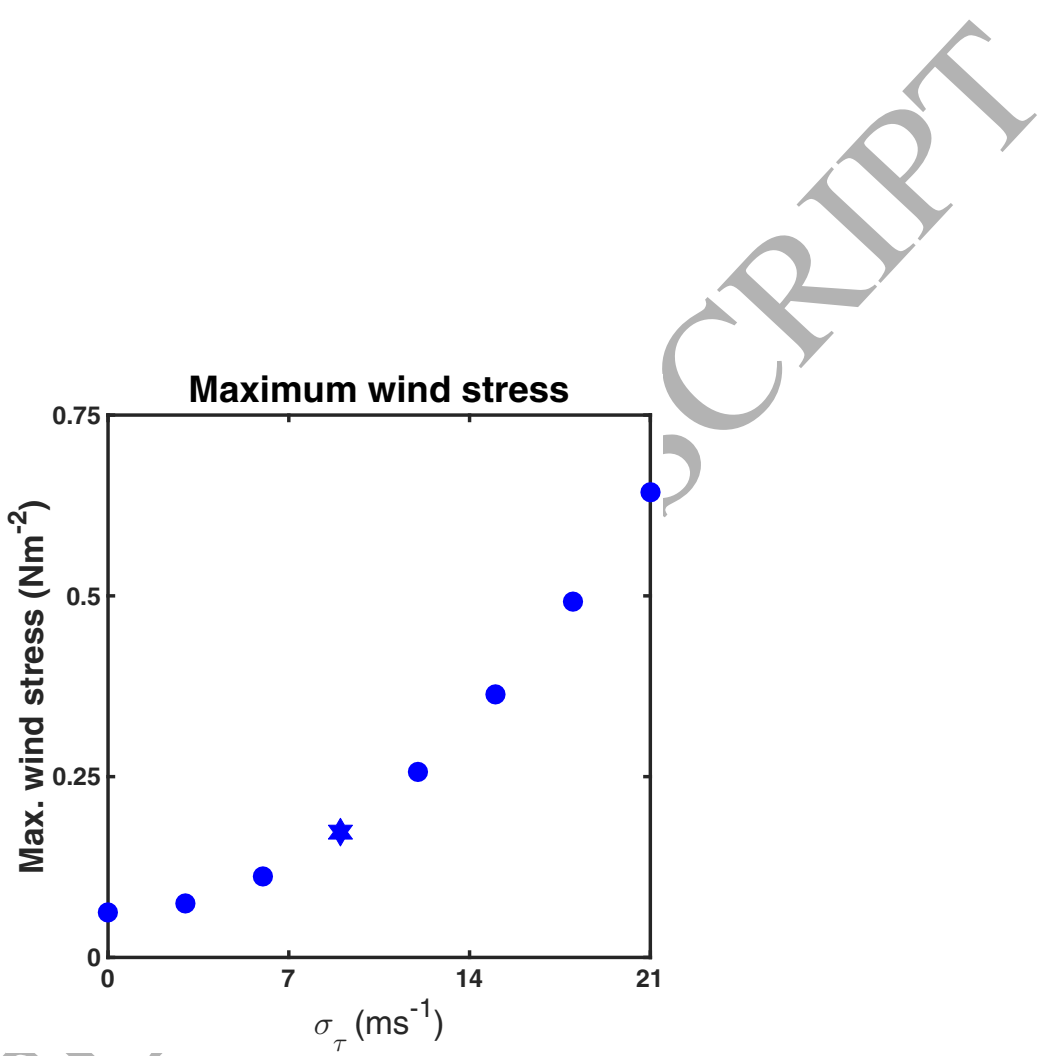

Figure 4: Variation in peak mean wind stress as the standard deviation of the atmospheric wind is varied. The peak mean wind stress of the control experiments is highlighted with a hexagram. 
a) Stochastic wind stress

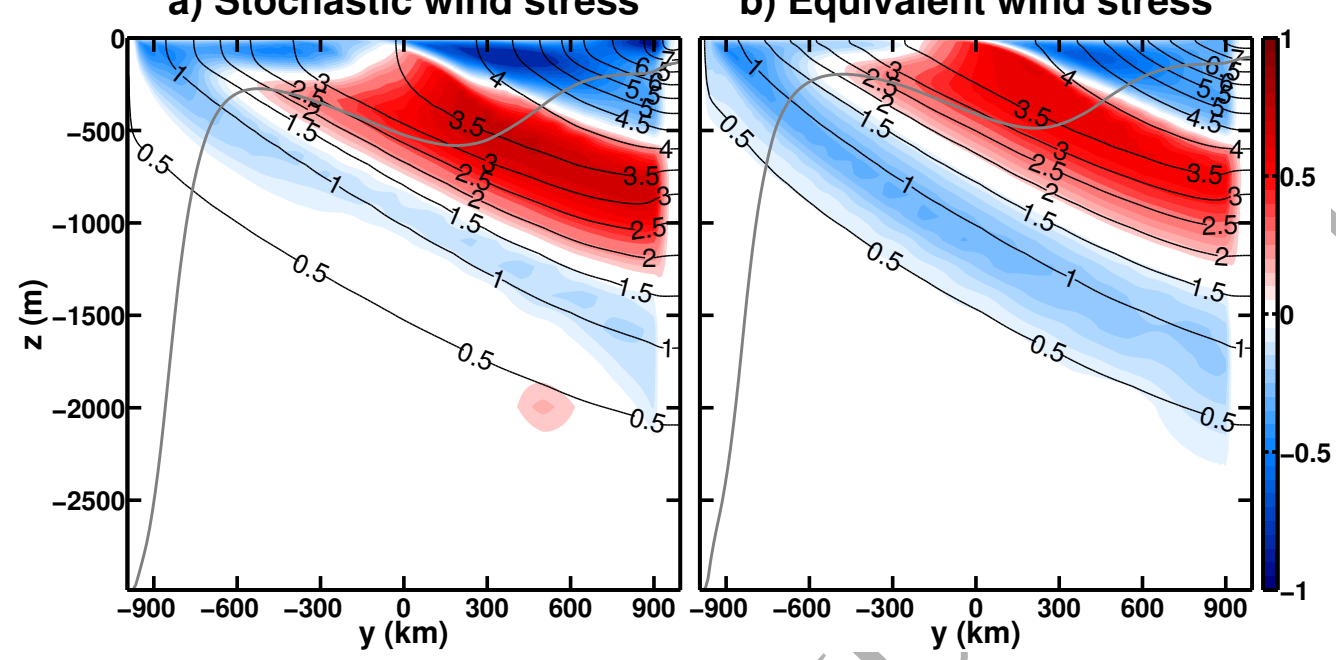

Figure 5: RMOC (in Sverdrups) at the control wind stress for (a) stochastic wind stress and (b) equivalent wind stress. Black contours are the zonal-time-average potential temperature $\left({ }^{\circ} \mathrm{C}\right)$ and the colours are the RMOC with red indicating clockwise flow. The grey contour is the mixed layer depth from KPP, defined as the depth at which the water is $0.8^{\circ} \mathrm{C}$ colder than the surface, see, e.g., Kara et al, (2000), for details. 

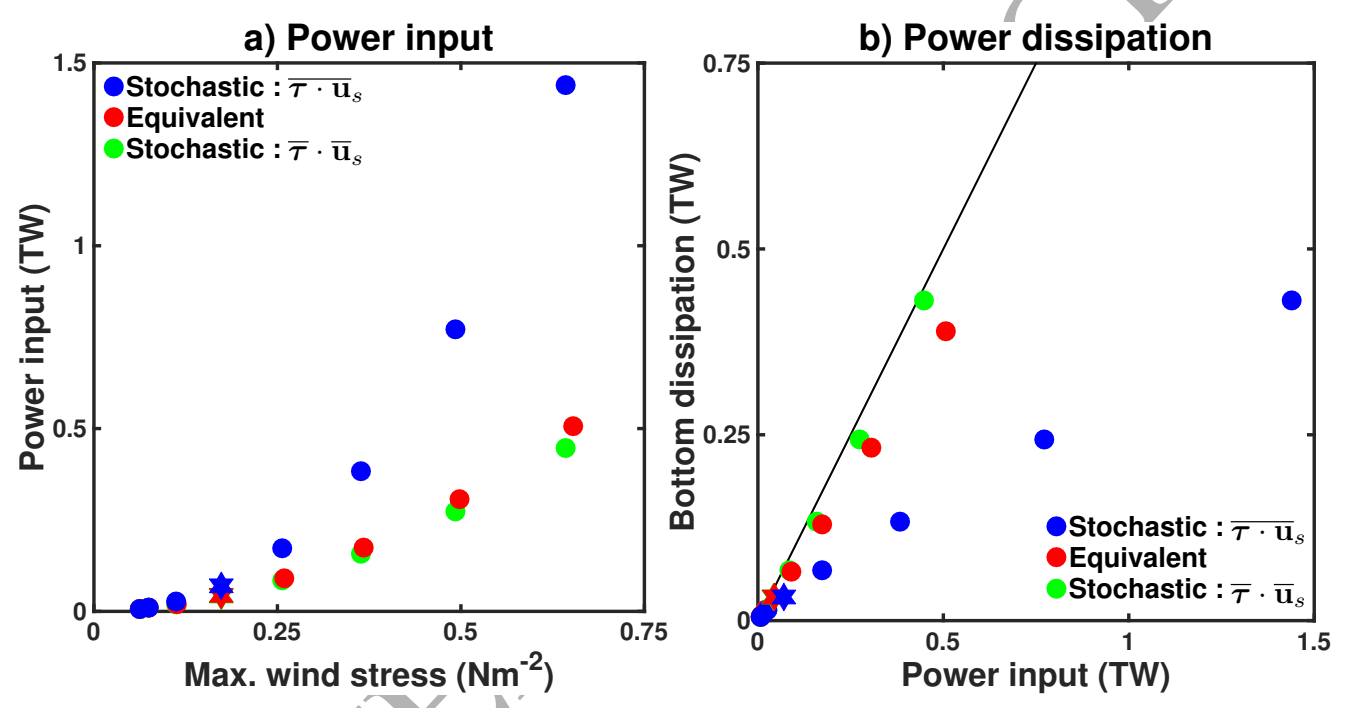

Figure 6: Sensitivity to wind stress changes of energy budget diagnostics. (a) Power input vs. maximum wind stress and (b) bottom EKE dissipation vs. power input. The thin black in line in (b) has a gradient of 1 and highlight the departure from the simple relationship of Eq. (8). The control experiments are highlighted with hexagrams. 
a) Vertical diffusivity via KPP

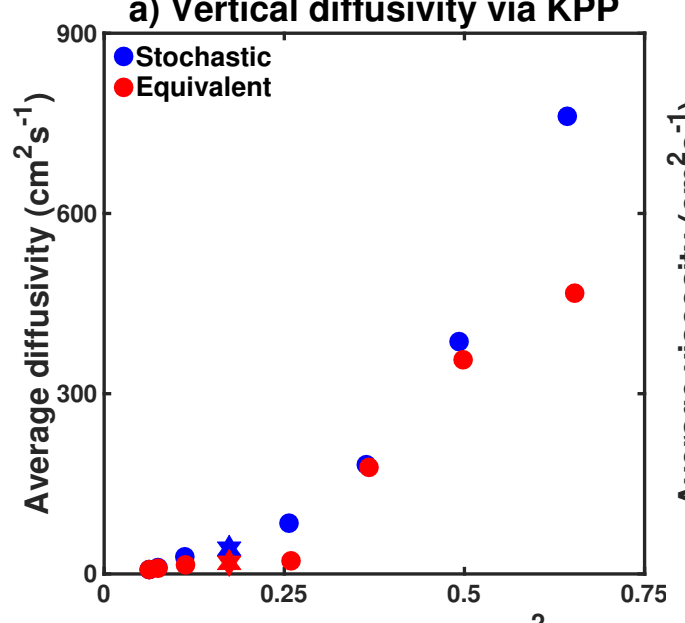

Max. wind stress $\left(\mathrm{Nm}^{-2}\right)$ b) Vertical viscosity via KPP

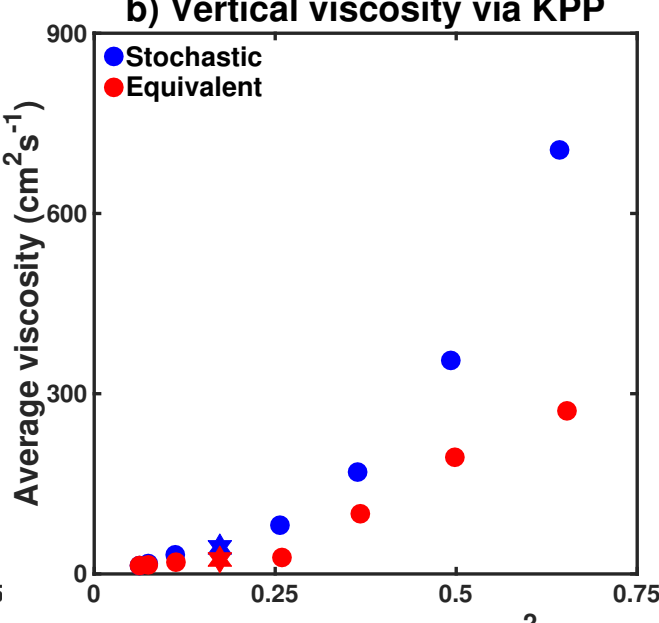

Max. wind stress $\left(\mathrm{Nm}^{-2}\right)$

Figure 7: Domain average (a) viscosity and (b) temperature diffusivity as provided by the KPP parameterisation versus the maximum wind stress. The control experiments are highlighted with hexagrams. 
a) Absolute magnitude

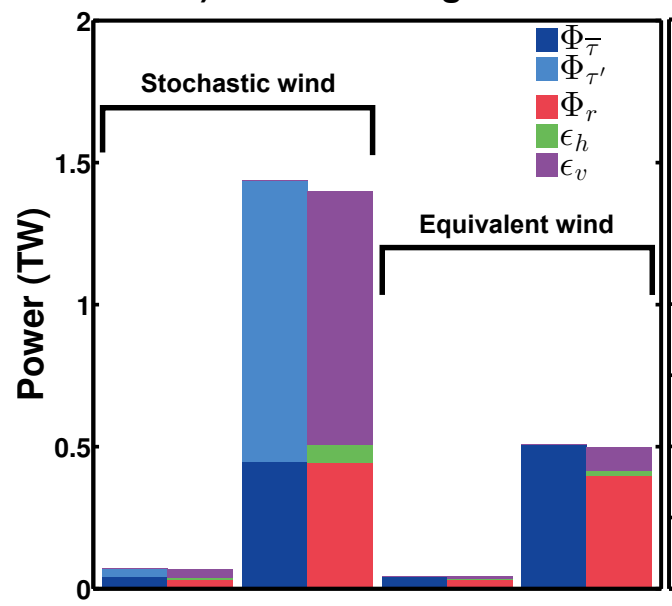

Control Extreme Control Extreme b) Relative magnitude

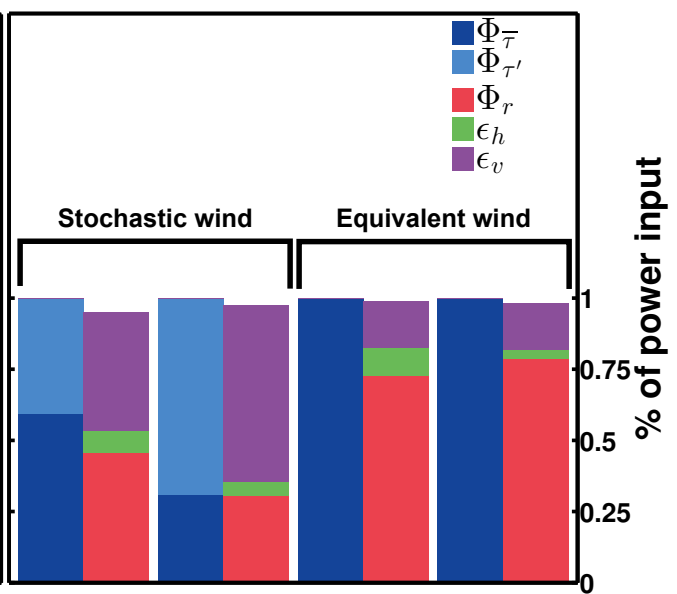

Control Extreme Control Extreme

Figure 8: Bar charts of the power budget for the control and extreme wind stress case for both stochastic and equivalent wind stress experiments. Presented as (a) absolute magnitude of the terms (b) relative to the total power input from the wind of each individual experiment. 
a) Control wind stress

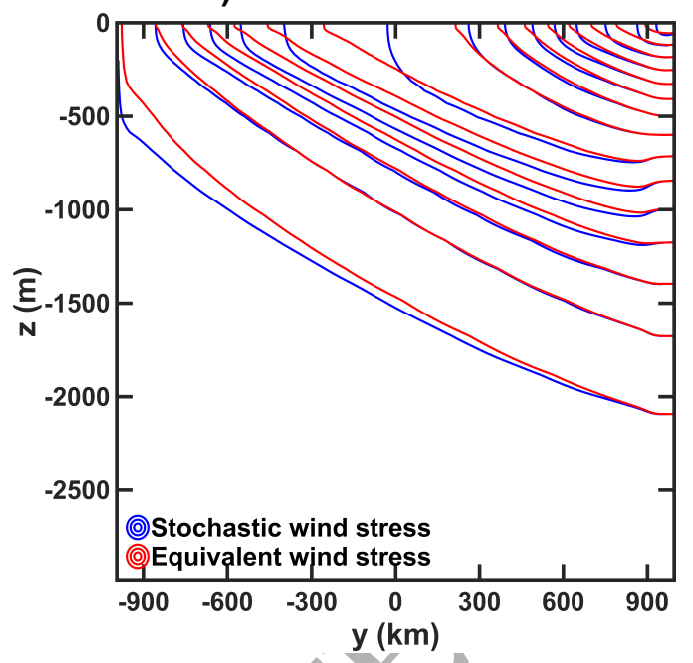

b) Extreme wind stress

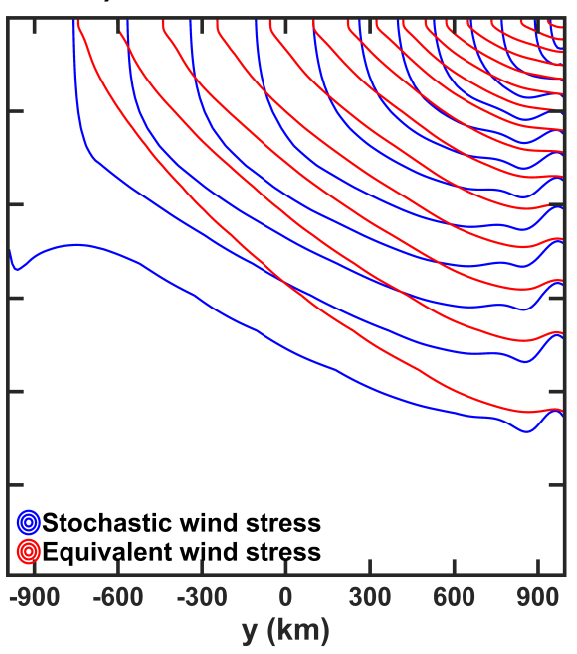

Figure 9: Contours of time and zonal average potential temperature, every $0.5^{\circ} \mathrm{C}$ starting at $0.5^{\circ} \mathrm{C}$, for paired stochastic (blue) and equivalent (red) wind stress experiments. (a) Control wind stress, with $\sigma_{\tau}=9 \mathrm{~ms}^{-1}$, for the stochastic experiment. (b) Extreme wind stress, with $\sigma_{\tau}=21 \mathrm{~ms}^{-1}$, for the stochastic experiment. 


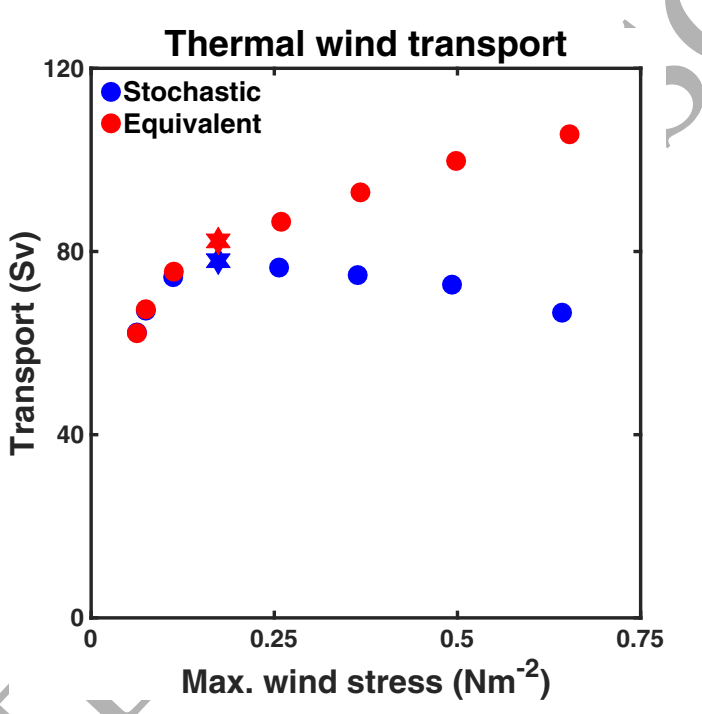

Figure 10: "Baroclinic" transport, as per $T_{t w}$ vs. maximum wind stress. The control experiments are highlighted with hexagrams. 


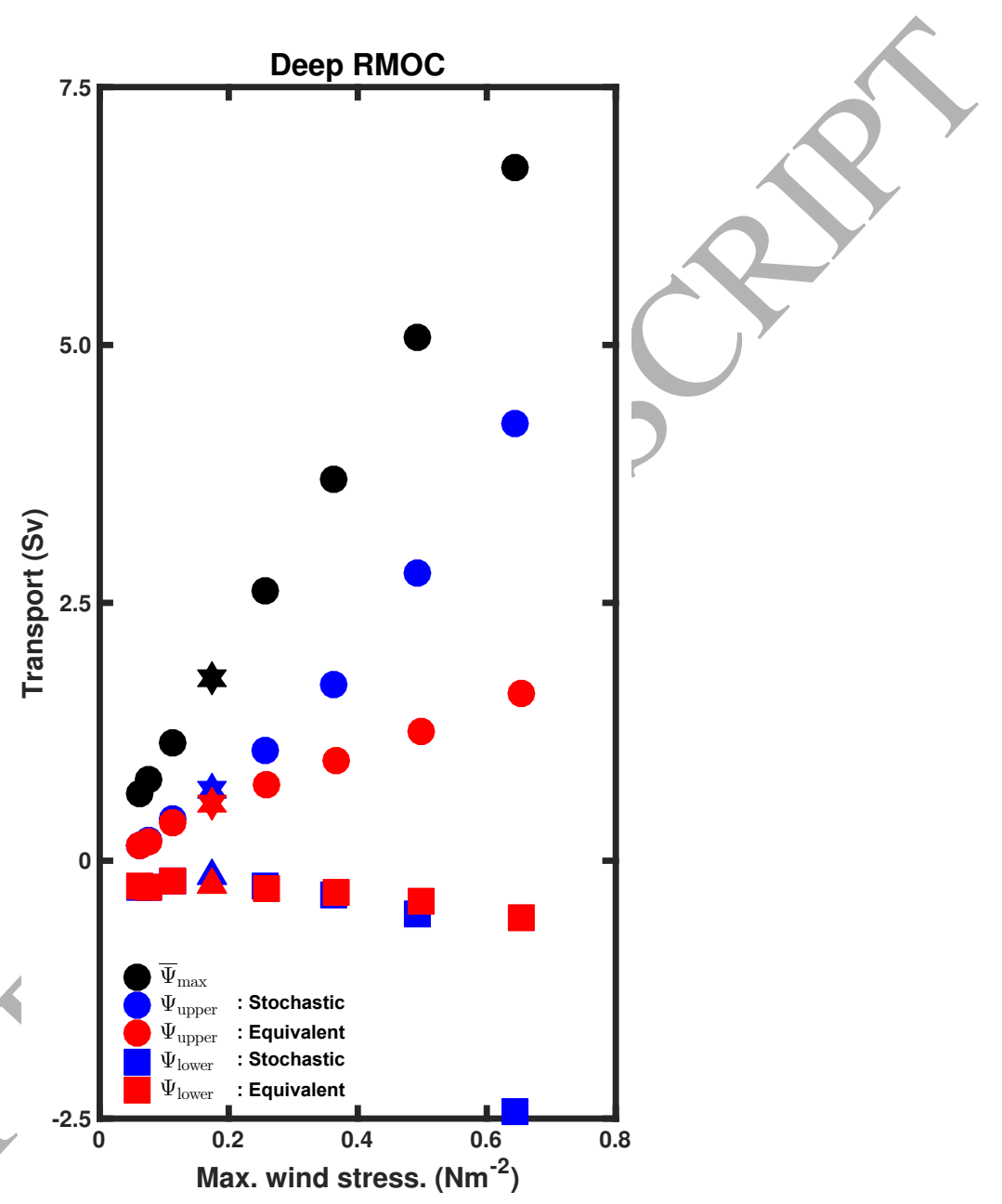

Figure 11: Sensitivity of the RMOC to changing wind stress across all experiments. Maximum Eulerian overturning in the domain $\left(\bar{\Psi}_{\max }\right.$, black dots) and maximum/minimum ( $\Psi_{\text {upper }} / \Psi_{\text {lower }}$, round/square) RMOC $100 \mathrm{~km}$ south of the northern restoring zone and below $500 \mathrm{~m}$ for the stochastic/equivalent wind stress experiments (blue/red). The control experiments are highlighted with hexagrams. 

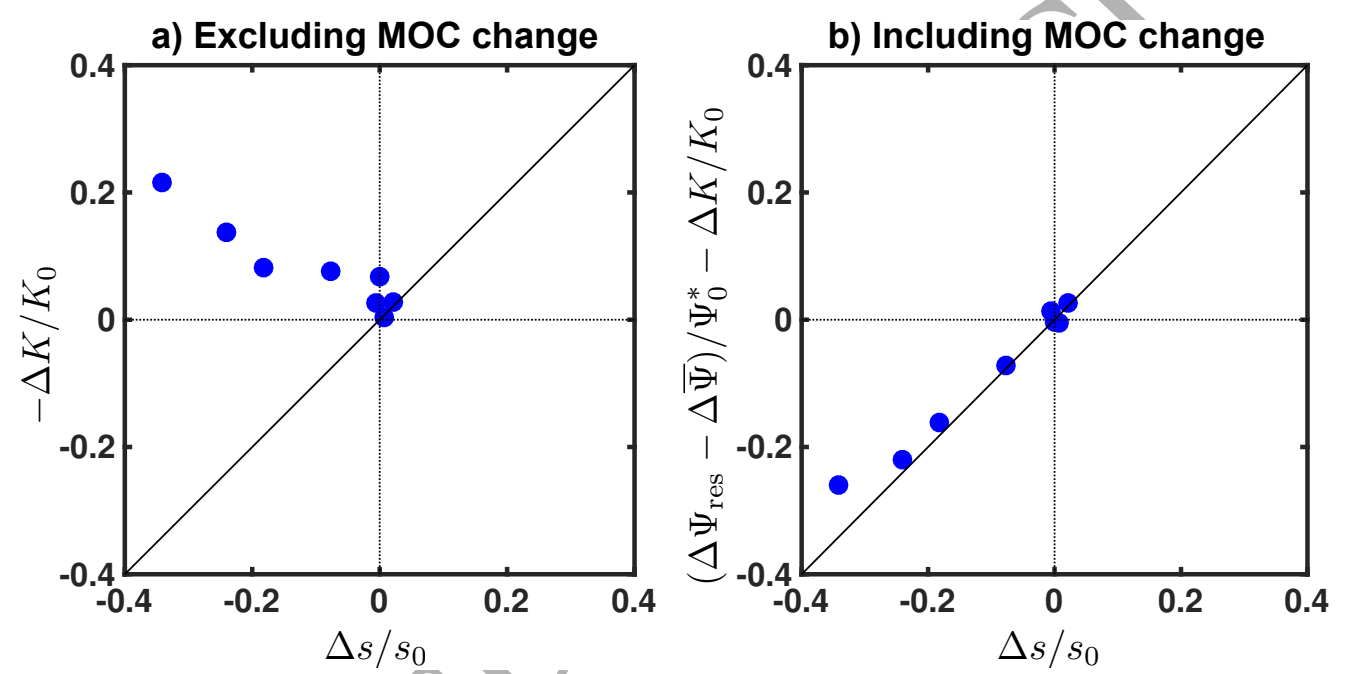

Figure 12: Quantitative tests of residual mean relationship between changes in eddy diffusivity and isopycnal slope. (a) Excluding any MOC changes, as per Eq. (21), (b) full relationship as per Eq. (20) including wind stress and MOC changes. The difference is taken between the equivalent and stochastic wind stress experiments with the equivalent wind stress experiment of each pair used as the initial state. The dotted lines cross at the origin and the solid line has a gradient of 1 . 
955

Tables

${ }_{956} \quad 1 \quad$ Model Parameters . . . . . . . . . . . . . . . 56

${ }_{957} 2$ Key diagnostics of the control experiments. Type of wind

${ }_{958} \quad$ stress, Domain average EKE, Total circumpolar transport,

959 Bottom transport, Thermal wind transport, $\Psi_{\text {upper }}, \Psi_{\text {lower }}$, do-

960 main average viscosity/diffusivity from $\operatorname{KPP}(A / K)$. 
Table 1: Model Parameters

Parameter
Domain size
Latitude of sponge edge
Domain depth

Boussinesq reference density Thermal expansion coefficient

Coriolis parameter Gradient in Coriolis parameter

Surface heat flux magnitude Peak wind speed

Bottom drag coefficient Sponge restoring timescale

Sponge vertical scale

Horizontal grid spacing

Vertical grid spacing

Vertical diffusivity $(\theta)$

Horizontal diffusivity $(\theta)$ Vertical viscosity (momentum)

\begin{tabular}{|c|c|c} 
Symbol & Value & Units \\
\hline$L_{x}, L_{y}$ & 1000,1990 & $\mathrm{~km}$ \\
$L_{\text {sponge }}$ & 1890 & $\mathrm{~km}$ \\
$H$ & 2985 & $\mathrm{~m}$ \\
$\rho_{0}$ & 1000 & $\mathrm{~kg} \mathrm{~m}^{-3}$ \\
$\alpha$ & $2 \times 10^{-4}$ & $\mathrm{~K}^{-1}$ \\
$f_{0}$ & $-1 \times 10^{-4}$ & $\mathrm{~km}$ \\
$\beta$ & $1 \times 10^{-11}$ & $\mathrm{~m}^{-1} \mathrm{~s}^{-1}$ \\
$Q_{0}$ & 10 & $\mathrm{~W} \mathrm{~m}^{-2}$ \\
$U_{0}$ & 7 & $\mathrm{~m} \mathrm{~s}^{-1}$ \\
$r_{b}$ & $1.1 \times 10^{-3}$ & $\mathrm{~m} \mathrm{~s}^{-1}$ \\
$t_{\text {sponge }}$ & 7 & $\mathrm{days}$ \\
$h_{e}$ & 1000 & $\mathrm{~m}$ \\
$\Delta x, \Delta y$ & 10 & $\mathrm{~km}^{2}$ \\
$\Delta z$ & $10-250$ & $\mathrm{~m}$ \\
$\kappa_{\mathrm{v}}$ & $10^{-5}$ & $\mathrm{~m}^{2} \mathrm{~s}^{-1}$ \\
$\kappa_{h}$ & 0 & $\mathrm{~m}^{4} \mathrm{~s}^{-1}$ \\
$A_{\mathrm{v}}$ & $10^{-3}$ & $\mathrm{~m}^{2} \mathrm{~s}^{-1}$ \\
$A_{4}$ & $10^{10}$ & $\mathrm{~m}^{4} \mathrm{~s}^{-1}$ \\
\hline
\end{tabular}

Horizontal hyperviscosity 
Table 2: Key diagnostics of the control experiments. Type of wind stress, Domain average EKE, Total circumpolar transport, Bottom transport, Thermal wind transport, $\Psi_{\text {upper }}$, $\Psi_{\text {lower }}$, domain average viscosity/diffusivity from $\operatorname{KPP}(A / K)$.

\begin{tabular}{c|c|c|c|c|c|c|c}
\hline Experiment & $\begin{array}{c}\text { EKE } \\
\left(\mathrm{cm}^{2} \mathrm{~s}^{-2}\right)\end{array}$ & $\begin{array}{c}T_{A C C} \\
(\mathrm{~Sv})\end{array}$ & $\begin{array}{c}\bar{T}_{b} \\
(\mathrm{~Sv})\end{array}$ & $\begin{array}{c}\bar{T}_{t w} \\
(\mathrm{~Sv})\end{array}$ & $\begin{array}{c}\Psi_{\text {upper }} \\
(\mathrm{Sv})\end{array}$ & $\begin{array}{c}\Psi_{\text {lower }} \\
(\mathrm{Sv})\end{array}$ & $\begin{array}{c}A / K \\
\left(\mathrm{~cm}^{2} \mathrm{~s}^{-1}\right)\end{array}$ \\
\hline Stochastic & 54 & 621 & 543 & 78 & 0.69 & -0.15 & $45 / 42$ \\
Equivalent & 49 & 630 & 548 & 82 & 0.55 & -0.23 & $24 / 18$ \\
\hline
\end{tabular}

